\title{
Development of a Dry-snow Satellite Algorithm and Validation at the CEOP Reference Site in Yakutsk
}

\author{
Hiroyuki TSUTSUI, Toshio KOIKE, and Tobias GRAF \\ Department of Civil Engineering, University of Tokyo, Tokyo, Japan
}

(Manuscript received 20 February 2006, in final form 20 November 2006)

\begin{abstract}
This paper presents a snow algorithm for the Advanced Microwave Scanning Radiometer (AMSR) and the AMSR for the Earth Observation System (AMSR-E). We validate the algorithm using snowdepth data recorded at the Coordinated Enhanced Observing Period (CEOP) Reference Site in Yakutsk, Russia. A new radiative transfer model for layered snow is developed by combining the 4-stream fast model and the dense media radiative model (DMRM); this model is then introduced into the new algorithm. The algorithm considers the effects of land-surface hydrological conditions under the snow layer and snow-particle grain size on brightness temperatures in the microwave region by using the multifrequency channels of AMSR and AMSR-E. The algorithm was validated at seven snow-measurement points within the CEOP Reference Site in Yakutsk from October 2002 to March 2003, corresponding to the first half of the third Enhanced Observing Period (EOP3).

We calculated the root mean square error (RMSE) based on the error between observed and estimated values and calculated the residual standard deviation $(R S D)$ for all verification periods. We also calculated the proportion and $R M S E$ of overestimated and underestimated values. The average $R M S E$ is low $(4.0 \mathrm{~cm})$ and the average $R S D$ is 2.8 , indicating only minor variation. In addition, $56 \%$ of values were overestimated, and the average RMSE of the overestimated values was $3.9 \mathrm{~cm}$; the average $R M S E$ for the $44 \%$ of values that were underestimated was $2.4 \mathrm{~cm}$. Accordingly, the estimated snow depth is in relatively good agreement with in situ data.

For the analyses undertaken at each site, we used the proposed algorithm to assess the influence of forest cover, frozen soil, and cloud cover on the process of estimating snow depth. We propose that such analyses are necessary when estimating snow depth.
\end{abstract}

\section{Introduction}

The land surface has various coverings, such as vegetation, snow, and soil. In addition, spatial and temporal heterogeneity of the land surface is much greater than that for the ocean. This variation makes it difficult to quantitatively assess variations in land-surface hydrology. A global-scale observation system for land-

Corresponding author: Hiroyuki Tsutsui, River \& Environmental Engineering Laboratory, Dept. of Civil Engineering, University of Tokyo, 7-3-1 Hongo, Bunkyoku, 113-8656 Tokyo, Japan. Email: tsutsui@hydra.t.u-tokyo.ac.jo

(C) 2007, Meteorological Society of Japan surface hydrological conditions is expected to enable improved predictions of variations in the long-term global water cycle and shortterm local water resources. To monitor snow conditions quantitatively, globally, and operationally, satellite remote sensing is the only viable method because it is impossible to install and operate in situ observation instruments with a uniformly high observation density over land within cold regions.

Many researchers have investigated the remote sensing of snow using the visible and near-infrared bands; however, this approach only provides estimates of the total area under snow. Subsequently, multi-frequency micro- 
wave remote-sensing was developed to estimate the characteristics of the atmosphere, including clouds, and the land surface, including both soil moisture and snow quantity.

The remote sensing of snow using the passive microwave approach has been investigated since the end of the 1960s when ground-based microwave radiometers showed potential in estimating snow-related parameters. A number of snow-water-equivalent retrieval algorithms have been developed (Chang et al. 1982; Hallikainen and Jolma 1986; Goodison et al. 1993; Koike and Suhama 1993) based on the basic relationship between the amount of snow and microwave radiative transfer, i.e., deeper snowpacks have lower microwave brightness temperatures (Mätzler 1987; Foster et al. 1991). Koike et al. (1999) developed an algorithm to simultaneously estimate snow depth and temperature using a snow microwave radiative transfer model, based on the work of England (1975), with fixed values of snow-particle grain size and density.

Wilson et al. (1999) developed a sophisticated algorithm to estimate snow depth, snow temperature, snow-particle grain size, and the fractional volume. This algorithm includes the dense media radiative transfer model (DMRM) developed by Tsang (1992) and the two-layer snowpack model of Marks (1988) combined with the snow-particle grain growth model proposed by Jordan (1991). Kelly et al. (2003) introduced the DMRM into a snow satellite algorithm that estimates snow water equivalent $(S W E)$ and that is based on the snow algorithm of Chang et al. (1987, 1991). In this algorithm, the effect of changing snow-particle grain size is considered using the classification system for seasonal snow cover proposed by Stume et al. (1995) and the experiential snow-particle grain-growth model of Sturm et al. (1997).

In the present paper, we propose a microwave radiative transfer model that combines DMRM (Tsang 1992) and the 4-stream fast radiative transfer model (Liu 1998). To make full use of the potential of satellite-based passive microwave sensors for the quantitative global monitoring of snow, we focus on the applicability of high-frequency $(89.0 \mathrm{GHz})$ channels in obtaining information on snow grain-size and low-frequency $(6.925 \mathrm{GHz})$ channels in evaluating the effects of land-surface conditions be- neath the snow layer. The frequencies of 18.7 and $36.5 \mathrm{GHz}$ are used to estimate snow depth and snow temperature. We then propose a drysnow satellite algorithm that can be used to automatically estimate snow depth and its water equivalent based on microwave radiative transfer theory.

The influence of cloud cover, vegetation, and soil moisture is a limiting factor when estimating snow depth based on microwave remote sensing. Although many researchers have investigated techniques that are useful in evaluating the effects of clouds, vegetation, and soil moisture, an algorithm that accurately reproduces actual conditions has yet to be developed.

In this paper, we chose not to introduce inaccurate evaluation techniques for clouds, vegetation, and soil moisture into our snow algorithm. This decision was made for the following reasons.

1) We sought to improve the estimation accuracy of snow depth for conditions where the influence of clouds, vegetation, and soil moisture can be neglected.

2) We sought to avoid indefinite errors that arise when using an imperfect evaluation technique.

In this research, we understand the limitations of clouds, vegetation, and soil moisture on estimating snow depth; we seek to establish a strategy to address these problems.

The algorithm was validated at seven snowmeasurement points within the Coordinated Enhanced Observing Period (CEOP) Reference Site in Yakutsk from October 2002 to March 2003, corresponding to the first half of the third Enhanced Observing Period (EOP3). We found that the estimated snow depth is in good agreement with in situ data.

\section{Development of a new snow algorithm}

In this paper, we describe two microwave radiative transfer models: the 4-stream fast model developed by Liu (1998) and the dense media radiative transfer model (DMRM) proposed by Tsang (1992). The advantage of DMRM (Tsang 1992) is the way that it takes account of the scattering effect. A conventional microwave radiative transfer model assumes that for spherical snow particles, scattering is mutually independent. Accordingly, radiation from the soil is scattered in many directions by 


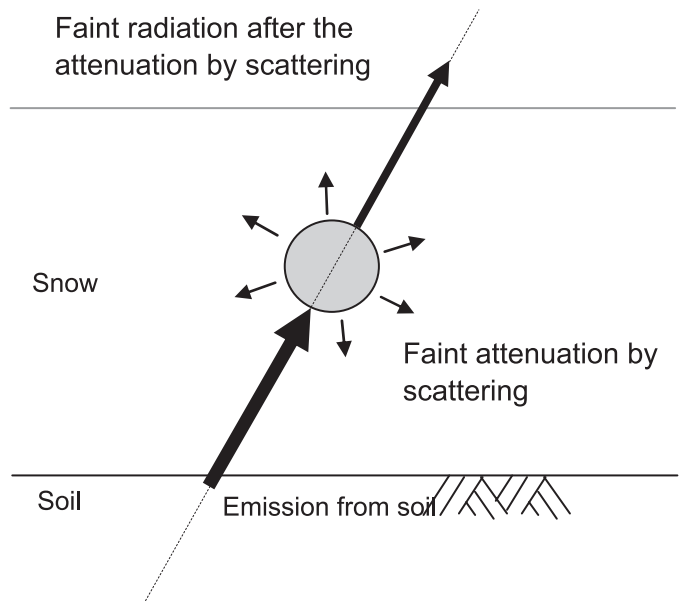

Fig. 1. Schematic sketch of the scattering effect according to a conventional radiative transfer model.

Strong radiation after the attenuation by

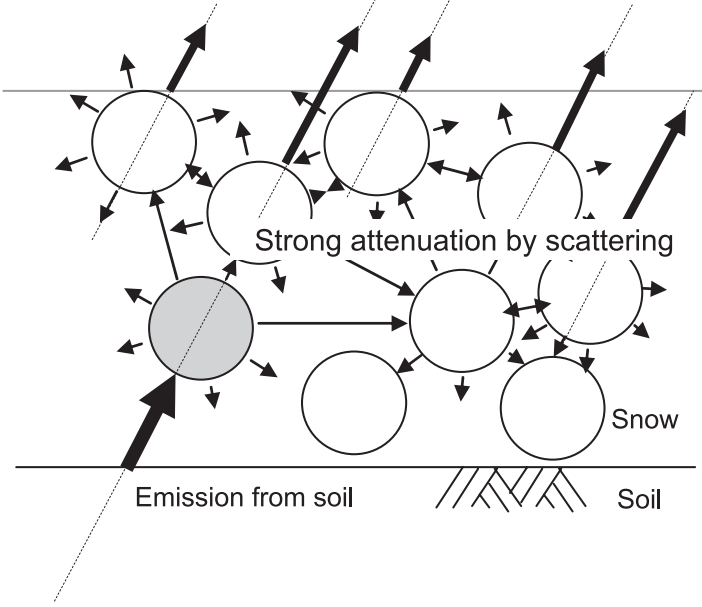

Fig. 2. Multiple scattering theories based on DMRM.

snow grains (Fig. 1) and the degree of attenuation by scattering is overestimated.

In contrast, DMRM assumes the condition whereby snow particles are mutually dependent. As shown in Fig. 2, once radiation from the soil is scattered by an arbitrary snow particle, a scattering process is introduced in which scattering occurs from many other particles. This scattering process is known as multiple scattering theories, and it expresses a realistic attenuation based on scattering by snow particles within snow.

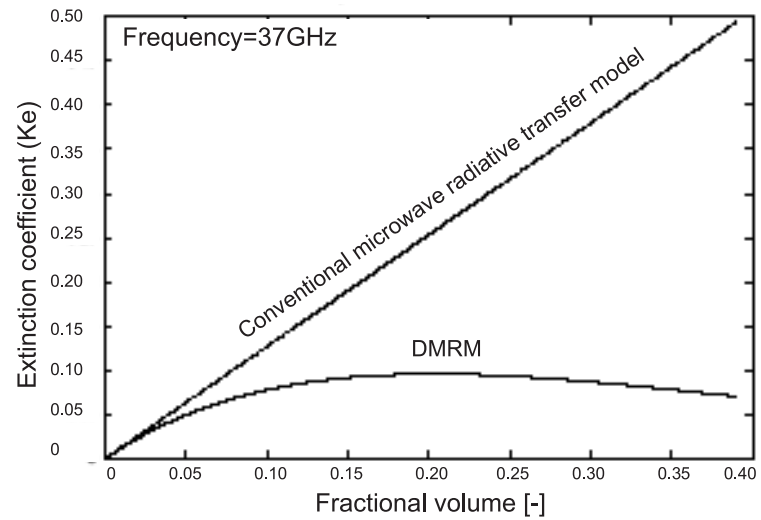

Fig. 3. Behavior of the extinction coefficient $(\mathrm{Ke})$ accompanying an increase in the fractional volume, as calculated using a conventional microwave radiative transfer model and DMRM.

In Fig. 3, the extinction coefficient $(K e)$ that accompanies an increase in the fractional volume is calculated using both a conventional model and DMRM. In the conventional model, the extinction coefficient $(K e)$ overestimates the accompanying increase in the fractional volume, whereas DMRM calculates the optimal extinction coefficient $(K e)$.

The 4-stream fast model, which was originally developed for radiative transfer processes in the atmosphere, is applied to snowpack at a wide range of frequencies, from 6.925 to $89 \mathrm{GHz}$, corresponding to the frequency coverage of AMSR and AMSR-E. The advantage of the 4-stream fast radiative transfer model is that it divides the space between the satellite and the land surface into many layers; the model then calculates the amount of radiation from the soil that is transmitted to each layer. Our algorithm uses a model in which radiation from the soil reaches a satellite via a simple layer structure consisting of a soil layer, a snow layer, and an atmospheric layer; however, we applied this model because in the future we can subdivide the snow and soil layers and insert a cloud cover into the atmospheric layer.

As shown in Fig. 4, our radiative transfer model calculates the following characteristic parameters: the extinction coefficient $(K e)$ and single scattering albedo $\left(\omega_{0}\right)$ of snow using DMRM and based on snow parameters (permittivity, fractional volume (density), grain size, 


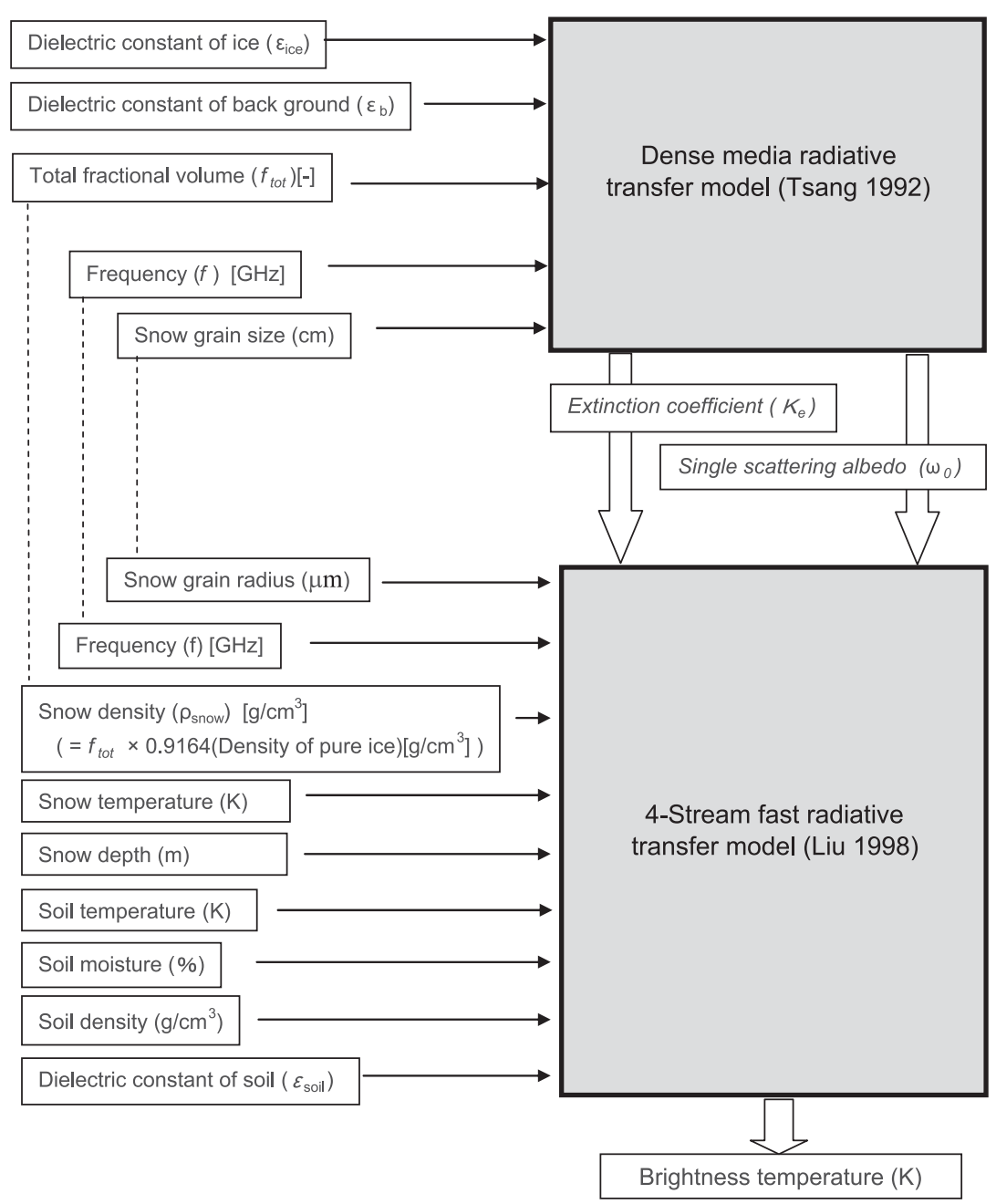

Fig. 4. Structure of the microwave radiative transfer model.

and frequency). The brightness temperature from the snow surface is calculated by inputting the characteristic parameters ( $K e$ and $\left.\omega_{0}\right)$, snow depth and temperature calculated using DMRT, and soil parameters (moisture, density, and permittivity) into the 4 -stream fast radiation transfer model.

The dielectric constant of ice was set to $\varepsilon_{i c e}=3.15-i \cdot 0.001$, based on the work of Cumming et al. (1952) and other studies (Vant et al. 1974; Lamb 1946; Lamb and Tumey 1949; Westphal 1965). The dielectric constant of the background, except for ice in snow, was set to $\varepsilon_{b}=1.00-i \cdot 0.000$ to target dry snow. The snow density was assumed to be $0.2 \mathrm{~g} \mathrm{~cm}^{-3}$ based on ground observations of snow in Fraser (USA) (Fig. 5) and Sapporo (Japan), as we also

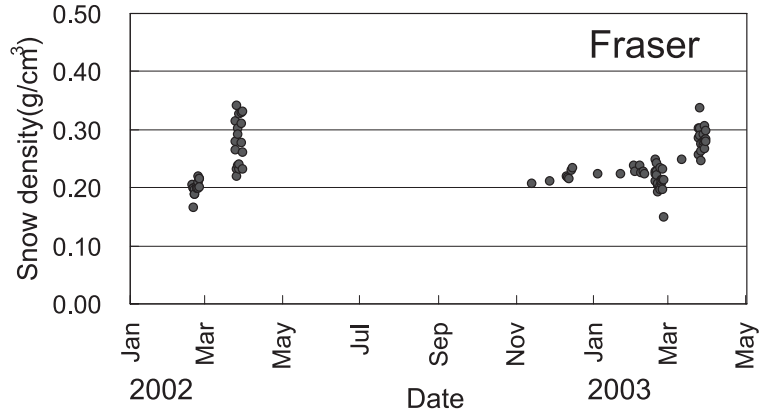

Fig. 5. Results of snow-density observations undertaken at Fraser, USA Observation periods: February 2002 to March 2002, October 2002 to March 2003. 


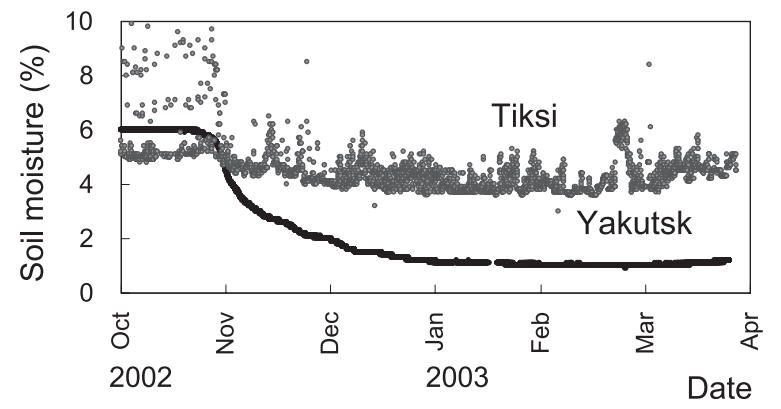

Fig. 6. Soil-moisture observations undertaken at Yakutsk and Tiksi, Russia.

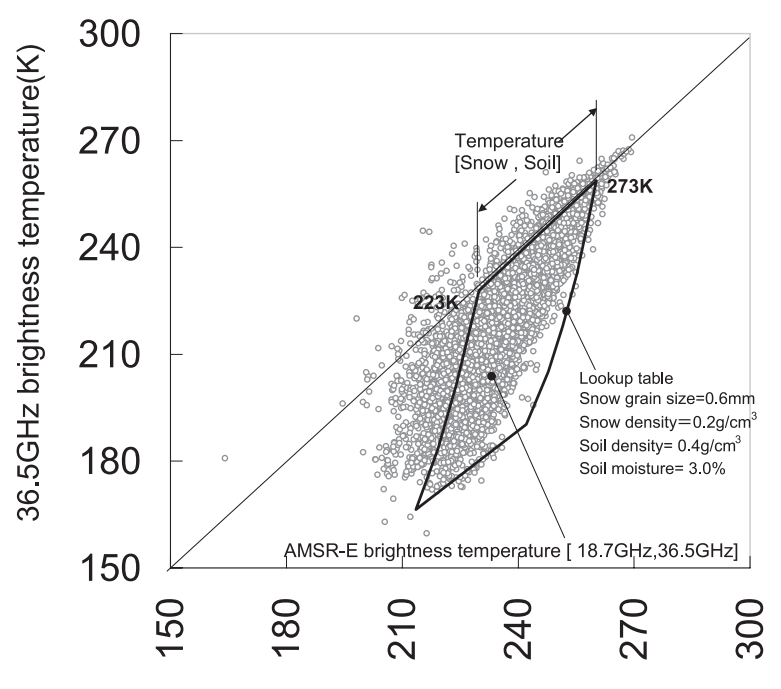

18.7 $\mathrm{GHz}$ brightness temperature $(\mathrm{K})$

Fig. 7. Daily values of AMSR-E brightness temperature recorded at the 70 GTS ground-based stations in the northern hemisphere. The lookup table is also shown.

considered simultaneously targeting snow in the northern hemisphere. The fractional volume was set to $0.218 \quad\left(=0.2 \mathrm{~g} \mathrm{~cm}^{-3} /\right.$ $0.9164 \mathrm{~g} \mathrm{~cm}^{-3}$ (density of pure ice)). The dielectric constant of soil was calculated based on Dobson's model (Dobson et al. 1985), and soil moisture was based on winter observations undertaken at Yakutsk and Tiksi, Russia (Fig. 6).

\subsection{Classification of the snowy region into four groups}

In Fig. 7, daily data of AMSR-E brightness temperature corresponding to the 70 GTS (global telecommunication system) groundbased stations in the northern hemisphere are distributed over a single lookup table. It is apparent from this figure that the distribution of various satellite brightness-temperatures is not covered by a single lookup table.

As described above, our proposed algorithm forms a lookup table based on the 18.7/ $36.5 \mathrm{GHz}$ brightness temperature calculated using the microwave radiative transfer model. The snow depth (and snow temperature) is estimated by inputting the satellite observation brightness temperature (18.7 and $36.5 \mathrm{GHz}$ ) into a lookup table. Therefore, the conditions relating to a given brightness temperature (18.7 and $36.5 \mathrm{GHz}$ ) in a lookup table are indispensable when estimating snow depth. Consequently, we applied the following technique to store the scattered distribution of brightness temperatures (18.7 and $36.5 \mathrm{GHz}$ ) in a lookup table.

As shown in the following formula, the brightness temperature from the snow surface $\left(T_{b}\right)$ is represented as the output from soil emission $\left(T_{\text {bsoil }}\right)$ dissipated by snow $\left(e^{-\tau_{\text {snow }}}\right)$.

$$
T_{b}=T_{b s o i l} \cdot e^{-\tau_{\text {snow }}}
$$

That is, the absolute amount of the brightness temperature from the snow surface and the horizontal position on the lookup table are mainly determined by the strength of soil emission. In this study, the soil emission is solely a variable of soil density because the soil moisture was assumed to be $3.0 \%$ and we assumed that snow temperature is equal to soil temperature.

Figure 8 was obtained by increasing the soil density from 0.2 to $0.8 \mathrm{~g} \mathrm{~cm}^{-3}$ in $0.2 \mathrm{~g} \mathrm{~cm}^{-3}$ steps, and having calculated the lookup table. The distribution of brightness temperature (18.7 and $36.5 \mathrm{GHz}$ ) scattered by soil emission at the four different soil densities can be stored in a lookup table. Furthermore, the following emission level was arbitrarily established using $6.925 \mathrm{GHz}$ with a wavelength that penetrates snowpack and that is able to detect soil. It is also possible to select a lookup table that is able to cover the distribution of brightness temperature (18.7 and $36.5 \mathrm{GHz}$ ) by selecting an emission level for the $6.925 \mathrm{GHz}$ brightness temperature (Fig. 8).

Emission level 1: $243 \mathrm{~K} \leqq \mathrm{~Tb} 06$

Emission level 2: $231 \mathrm{~K} \leqq \mathrm{~Tb} 06<243 \mathrm{~K}$ 


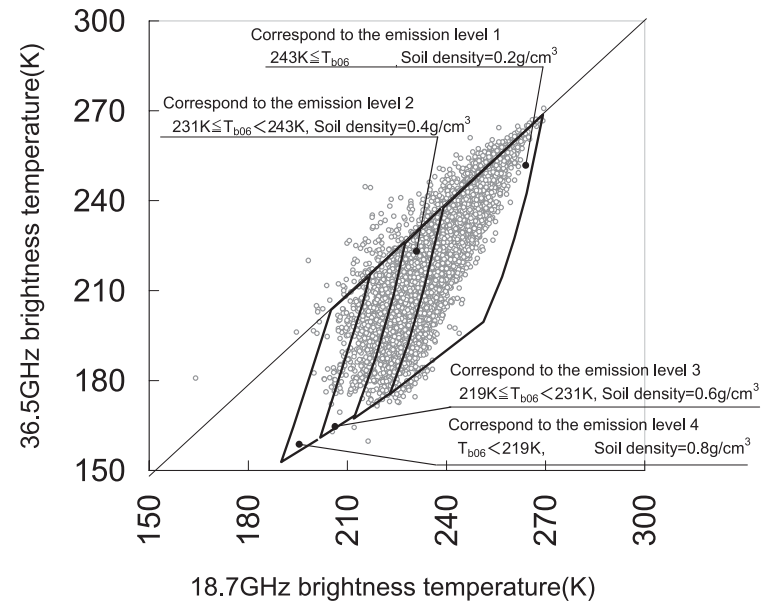

Fig. 8. Position on the lookup table corresponding to the emission level.

Emission level 3: $219 \mathrm{~K} \leqq \mathrm{~Tb} 06<231 \mathrm{~K}$ Emission level 4: Tb06 $<219 \mathrm{~K}$

\subsection{Construction of lookup tables}

For each ground-emission level, a lookup table is generated that represents the relationship between the brightness temperatures at 18.7 and $36.5 \mathrm{GHz}$ and snow depth and physical temperature, corresponding to each grain size and constant snow density $\left(0.2 \mathrm{~g} \mathrm{~cm}^{-3}\right)$. First, brightness temperature at 18.7 and $36.5 \mathrm{GHz}$ is calculated by inputting snow depth and snow temperature into the microwave radiative transfer model. The snow depth is varied from 1 to $200 \mathrm{~cm}$, and the snow temperature changes from $223 \mathrm{~K}\left(-50^{\circ} \mathrm{C}\right)$ to $273 \mathrm{~K}\left(0^{\circ} \mathrm{C}\right)$. Second, the result of the calculation is reversed to obtain the snow depth and temperature by inputting the observed brightness temperature with a $1 \mathrm{~K}$ interval. As shown in Fig. 9, snow depth and snow temperature are estimated by inputting satellite-derived 18.7 and $36.5 \mathrm{GHz}$ brightness temperature data into the lookup table.

\subsection{Calculation of the brightness temperature at $89 \mathrm{GHz}$ and selection of optimal grain size}

Previous SWE algorithms assumed snow grains of a fixed size; accordingly, the difference between the assumed and actual size of a snow grain resulted in a reduction in the accuracy of $S W E$ estimates. This effect is pronounced for deep snow. The $S W E$ algorithm into which the

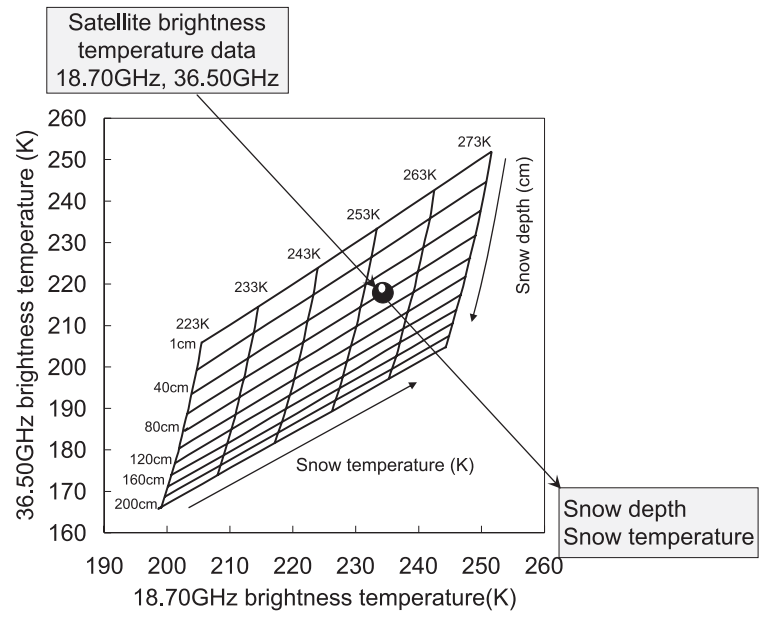

Fig. 9. Estimation of snow depth using the lookup table.

snow-particle growth model was introduced was developed in recent years to solve this problem; however, we consider that it is difficult to estimate global snow, which has varying regional characteristics, on the basis of only one or several snow-grain growth models. Consequently, we devised a technique that can be used to estimate changes in the size of snow particles from satellite observation data, independent of regional characteristics.

We used high-frequency microwave satellite data to estimate changes in snow particles because high-frequency microwaves are sensitive to the dispersion effect related to changes in snow grains. This is shown in the behavior of the scattering coefficient (Ks) (Fig. 10).

In the past, many researchers have applied brightness temperatures of 19 and $37 \mathrm{GHz}$ to the $S W E$ algorithm and in doing so have demonstrated the validity of such an approach. The Japan Aerospace Exploration Agency (JAXA) then stated the necessity of the introduction of a $S W E$ algorithm with a high frequency of $89 \mathrm{GHz}$ to detect changes in snow particles. Consequently, we considered the use of highfrequency satellite microwave data at $89 \mathrm{GHz}$, which is able to detect changes in snow particles.

Essentially, the size of a snow grain is a geometric value and should be independent of variations in frequency; however, our microwave radiation transfer model has a different grainsize range for every frequency; this is a problem 


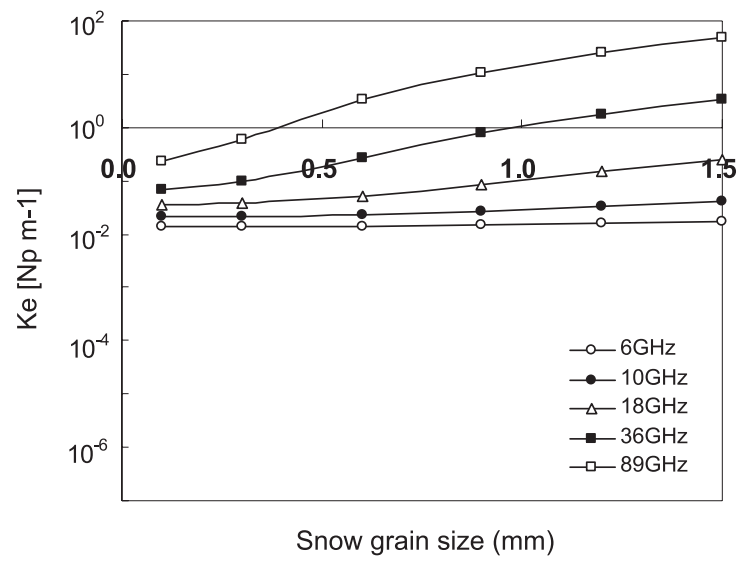

(a) Extinction coefficient (Ke)

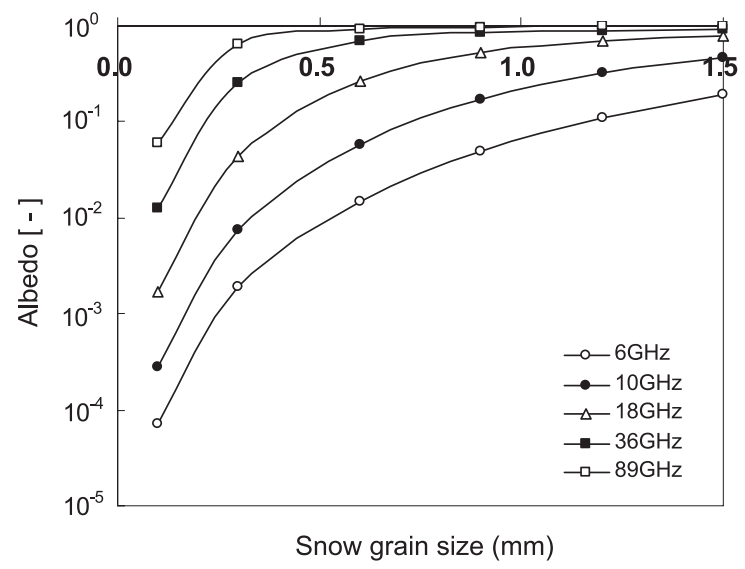

(b) Single scattering coefficient $\left(\omega_{0}\right)$

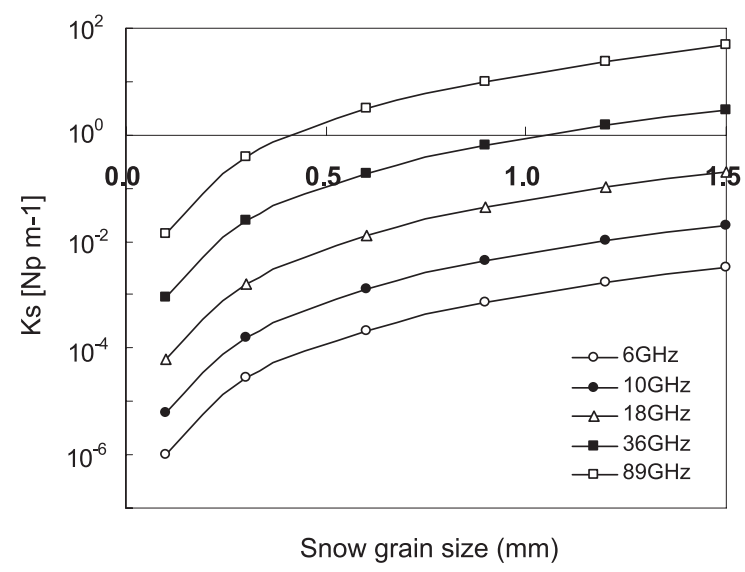

(c) Scattering coefficient $(\mathrm{Ke})$

Fig. 10. Behavior of the extinction coefficient $(K e)$, single scattering albedo $\left(\omega_{0}\right)$, and scattering coefficient $(K s)$ with changes in particle size, as based on a microwave radiative transfer model. (Snow density $=0.2 \mathrm{~g} \mathrm{~cm}^{-3}$, Dielectric constant of snow $=3.15 i \times 0.001$ ). that needs to be improved upon. We examined the grain-size change interval at $89.0 \mathrm{GHz}$ based on the ratio of satellite- and modelcalculated brightness temperature. When a grain size of $0.5 \mathrm{~mm}$ was assumed at the GTS station, the minimum discrepancy between the observed brightness-temperature value and model calculation value was observed at the $36.5 \mathrm{GHz}$ band (Fig. 11, middle line). Therefore, $0.5 \mathrm{~mm}$ was judged to be the optimal grain size. In contrast, when this grain size $(0.5 \mathrm{~mm})$ was used at the $89.0 \mathrm{GHz}$ band, we found a large discrepancy between the observed and calculated values (Fig. 11, upper line). This means that the grain-size change intervals differ between 36.5 and $89.0 \mathrm{GHz}$. When $0.3 \mathrm{~mm}$ was assumed, the scale of the discrepancy was reduced by a small amount. We gradually reduced the grain size at $89.0 \mathrm{GHz}$ and investigated the grain size at $89.0 \mathrm{GHz}$ that is equivalent to $0.5 \mathrm{~mm}$ (ratio of 1.05 ) at $36.5 \mathrm{GHz}$. As a result, we concluded that the ratio at $89.0 \mathrm{GHz}$ is set to 1.05 when the grain size is assumed to be $0.08 \mathrm{~mm}$ (Fig. 11, lower line). This finding has the following implications.

- When the grain size at $36.5 \mathrm{GHz}$ is $0.5 \mathrm{~mm}$, the grain size at $89.0 \mathrm{GHz}$ is set to $0.08 \mathrm{~mm}$ (when the grain size at $36.5 \mathrm{GHz}$ is $0.6 \mathrm{~mm}$, the grain size at $89.0 \mathrm{GHz}$ is set to $0.12 \mathrm{~mm}$ ).

- The grain-size change interval $(1 \mathrm{~mm})$ for $36.5 \mathrm{GHz}$ is equivalent to $0.04 \mathrm{~mm}$ for $89.0 \mathrm{GHz}$.

This analysis was also undertaken for other GTS stations, with the same results. Furthermore, we found that the ratio of 2.5 $(=0.1 \mathrm{~mm} / 0.04 \mathrm{~mm})$ in grain-size change interval was equivalent to the ratio of 2.5 $(\fallingdotseq 89.0 \mathrm{GHz} / 36.5 \mathrm{GHz})$ in frequency.

That is, when a grain size changes by $0.10 \mathrm{~mm}$ at $36.5 \mathrm{GHz}$, the change in grain size at $89 \mathrm{GHz}$ in the model is set to $0.04 \mathrm{~mm}$. This value is derived from the ratio of a certain frequency, as expressed in the following formula:

\section{Size variation of $89 \mathrm{GHz}$}

$$
\begin{aligned}
= & 0.10 \mathrm{~mm}(\text { Size variation of } 36.5 \mathrm{GHz}) \\
& \div \frac{\mathbf{8 9 . 0 ~ G H z}}{\mathbf{3 6 . 5 ~ G H z}} \\
= & 0.04 \mathrm{~mm}
\end{aligned}
$$




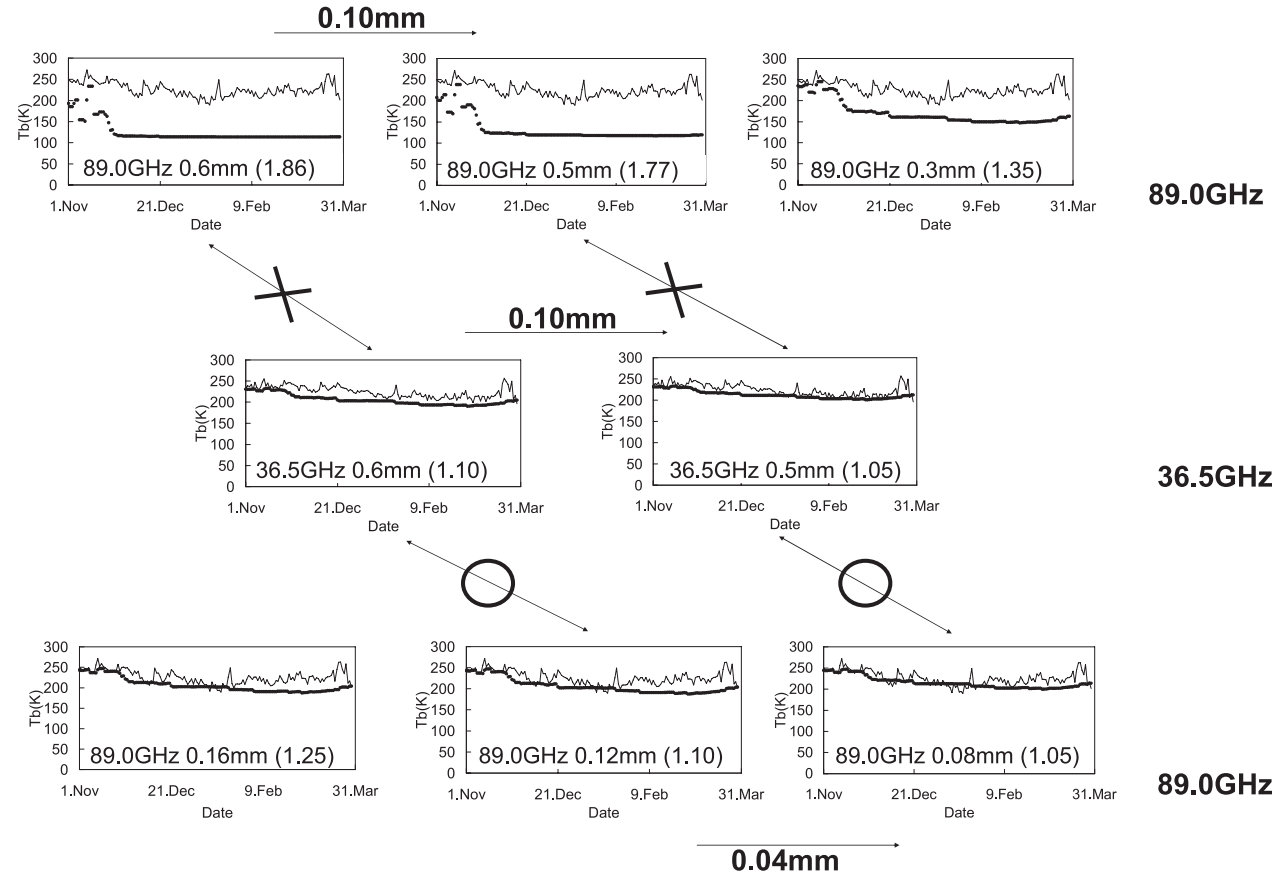

Fig. 11. Example of the grain-size change interval at $89 \mathrm{GHz}$ band based on brightness temperature $(\mathrm{Tb})$. Solid line: Satellite brightness temperature, thick dotted line: calculated brightness temperature based on the microwave radiative transfer model. Terms used in the graph: frequency, assumed grain size based on the microwave radiative transfer model (average of the ratio of calculated (model) and observed (satellite) values).

We then calculated the brightness temperature (36.5 GHz: Tbcal36 (d36), 89 GHz: Tbcal89 (d36)) using the microwave radiative transfer model and snow depth data recorded from October 2002 to March 2003 at the northernhemisphere GTS ground-observation stations, as well as making use of the following assumed parameters:

- snow and soil temperature $=248 \mathrm{~K}$;

- snow density $=0.2 \mathrm{~g} \mathrm{~cm}^{-3}$;

- soil density $=0.5 \mathrm{~g} \mathrm{~cm}^{-3}$;

- soil moisture $=3.0 \%$

For this period, the grain size for $36.5 \mathrm{GHz}$ was considered to be $0.4-1.4 \mathrm{~mm}$; the use of a corresponding grain size for $89 \mathrm{GHz}$ led to the four cases shown in Table 1.

The relative error $\left(36.5 \mathrm{GHz}: T_{b 36 e r r o r}\right.$, $89 \mathrm{GHz}: T_{b 89 e r r o r}$, [\%]) between the satelliteobservation-derived and calculated brightness temperatures for each station (average from October 2002 to March 2003 for each station $\left(T_{b o b s 36}, T_{b o b s 89}\right)$ ) was calculated using the fol-
Table 1. Details of the corresponding grain sizes for $89 \mathrm{GHz}$

\begin{tabular}{l|c|c|c|c}
\hline $\begin{array}{l}36.5 \mathrm{GHz} \\
\text { Grain } \\
\text { size }(\mathrm{mm})\end{array}$ & \multicolumn{4}{|c}{$89.0 \mathrm{GHz}$ Corresponsive grain size $(\mathrm{mm})$} \\
\cline { 2 - 5 } & Case 1 & Case 2 & Case 3 & Case 4 \\
\hline 0.40 & 0.16 & 0.12 & 0.08 & 0.04 \\
\hline 0.50 & 0.20 & 0.16 & 0.12 & 0.08 \\
\hline 0.60 & 0.24 & 0.20 & 0.16 & 0.12 \\
\hline 0.70 & 0.28 & 0.24 & 0.20 & 0.16 \\
\hline 0.80 & 0.32 & 0.28 & 0.24 & 0.20 \\
\hline 0.90 & 0.36 & 0.32 & 0.28 & 0.24 \\
\hline 1.00 & 0.40 & 0.36 & 0.32 & 0.28 \\
\hline 1.10 & 0.44 & 0.40 & 0.36 & 0.32 \\
\hline 1.20 & 0.48 & 0.44 & 0.40 & 0.36 \\
\hline 1.30 & 0.52 & 0.48 & 0.44 & 0.40 \\
\hline 1.40 & 0.56 & 0.52 & 0.48 & 0.44 \\
\hline & & & &
\end{tabular}




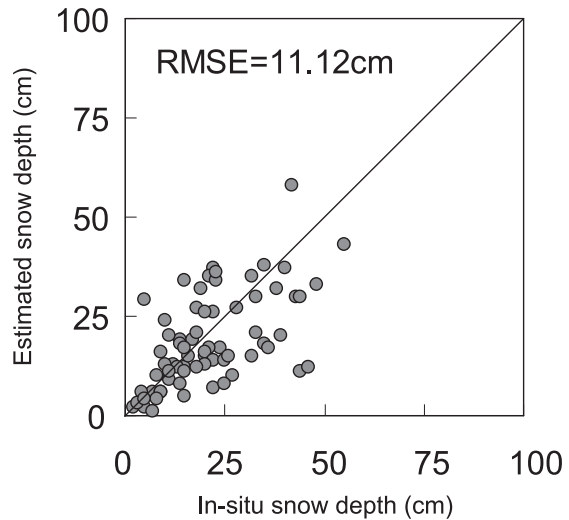

(a) Range in grain size: $0.4-0.9 \mathrm{~mm}$

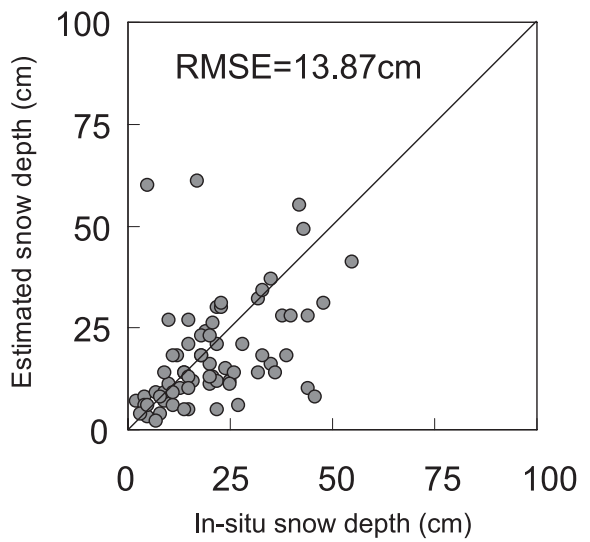

(b) Range in grain size: $0.4-1.0 \mathrm{~mm}$

Fig. 12. Example of error evaluation based on average $R M S E$ for the period from October 2002 to March 2003 at the 70 ground-based stations located in the northern hemisphere.

lowing formula:

$T_{b 36 \text { error }}\left(d_{36}\right)=\left|\frac{T_{b o b s 36}-T_{b c a l 36}\left(d_{36}\right)}{T_{b o b s 36}}\right| \times 100(\%)$

$d_{36}=0.4,0.5, \ldots, 1.4 \mathrm{~mm}$

$T_{b 89 e r r o r}\left(d_{36}\right)=\left|\frac{T_{b o b s 89}-T_{b c a l 89}\left(d_{36}\right)}{T_{b o b s 89}}\right| \times 100(\%)$

$d_{36}=0.4,0.5, \ldots, 1.4 \mathrm{~mm}$

If the grain size for $89 \mathrm{GHz}$ corresponds to the grain size for $36.5 \mathrm{GHz}$, then $T_{b 36 e r r o r}$ and $T_{b 89 e r r o r}$ must show a good fit. In this case, the $R M S E$ of the relative errors was calculated.

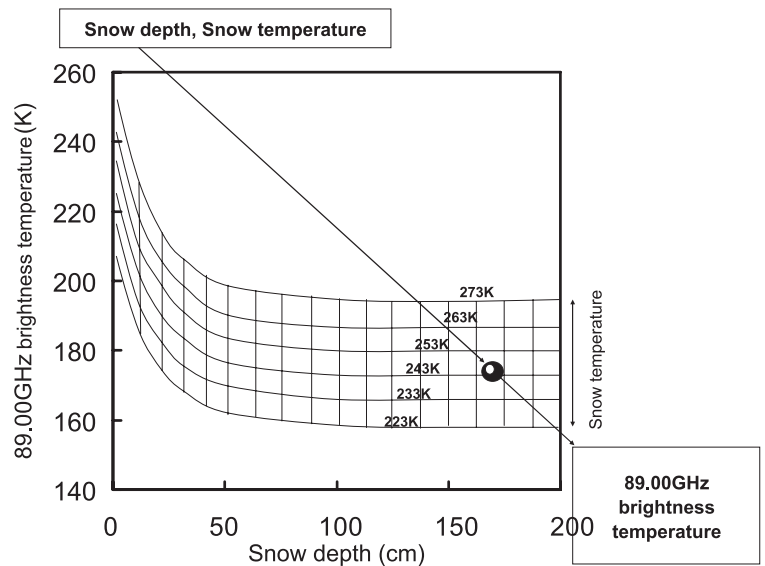

Fig. 13. Estimation of the brightness temperature at $89 \mathrm{GHz}$.

The RMSE is $40.2 \%$ for Case $1,25.8 \%$ for Case 2, $13.6 \%$ for Case 3 , and $11.5 \%$ for Case 4 . Therefore, the grain size for $89 \mathrm{GHz}$ that corresponds to the grain size for $36.5 \mathrm{GHz}$ is that shown in Case 4.

Case 4:

36.5 GHz Grain size:

$0.40,0.50, \ldots, 0.90, \ldots, 1.30,1.40 \mathrm{~mm}$

$89.0 \mathrm{GHz}$ corresponsive grain size:

$0.04,0.08, \ldots, 0.24, \ldots, 0.40,0.44 \mathrm{~mm}$

Furthermore, the range in grain size $(36.5 \mathrm{GHz})$ in the algorithm was set at $0.4-$ $0.9 \mathrm{~mm}$. This range was adjusted based on verification undertaken by comparing the snow depth estimated using the algorithm (AMSR-E brightness temperature data) and in situ measurements of snow depth undertaken at GTS ground-based stations in the northern hemisphere over the period October 2002 to March 2003. Verification involved evaluation of the RMSE between the observed and estimated snow depth and visual evaluation of adjustments to the patterns of variation in timeseries data.

Figure 12 shows an example of error evaluation based on $R M S E$ data for average values from October 2002 to March 2003, as recorded at the 70 ground-based stations in the northern hemisphere. For the algorithm with a range in grain size from 0.4 to $0.9 \mathrm{~mm}$ (Fig. 12a), the error in snow depth based on RMSE was $11.12 \mathrm{~cm}$; however, when the maximum grain 

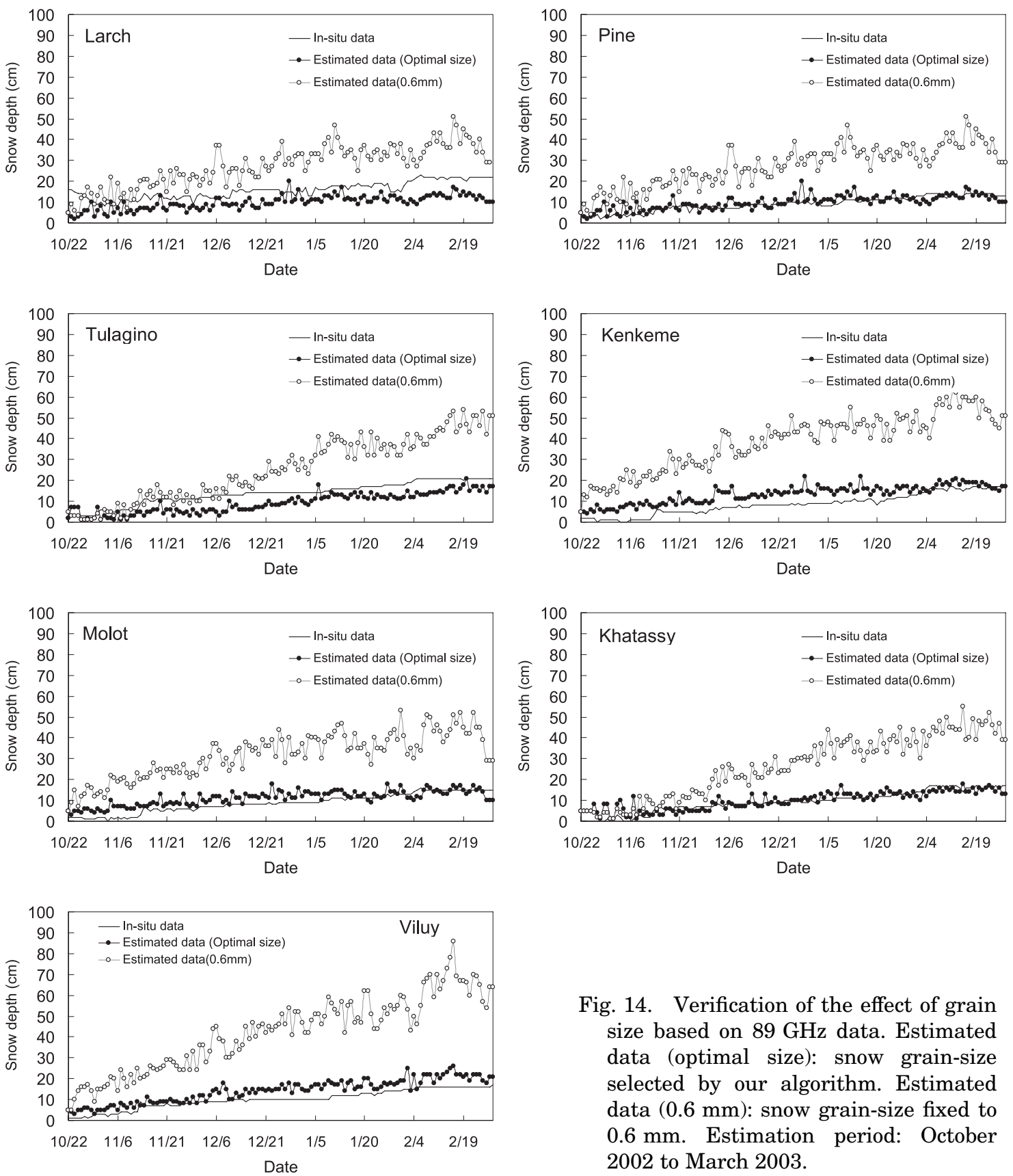

Fig. 14. Verification of the effect of grain size based on $89 \mathrm{GHz}$ data. Estimated data (optimal size): snow grain-size selected by our algorithm. Estimated data $(0.6 \mathrm{~mm})$ : snow grain-size fixed to $0.6 \mathrm{~mm}$. Estimation period: October 2002 to March 2003.

size was increased to $1.0 \mathrm{~mm}$ (Fig. 12b), the error involved in estimating snow depth increased to $13.87 \mathrm{~cm}$. That is, the accuracy of estimates of snow depth decreased when the maximum grain size was increased from 0.9 to $1.0 \mathrm{~mm}$. Thus, we examined different size ranges by trial and error and found that the range between 0.4 and $0.9 \mathrm{~mm}$ was optimal for

grains considered in the microwave radiative transfer model.

In our algorithm, the brightness temperature at $89 \mathrm{GHz}$ is calculated by inputting data on snow depth, temperature, and grain size derived from the lookup table at 18.7 and $36.5 \mathrm{GHz}$, as shown in Fig. 13. The optimal grain size of snow is selected by comparing the 


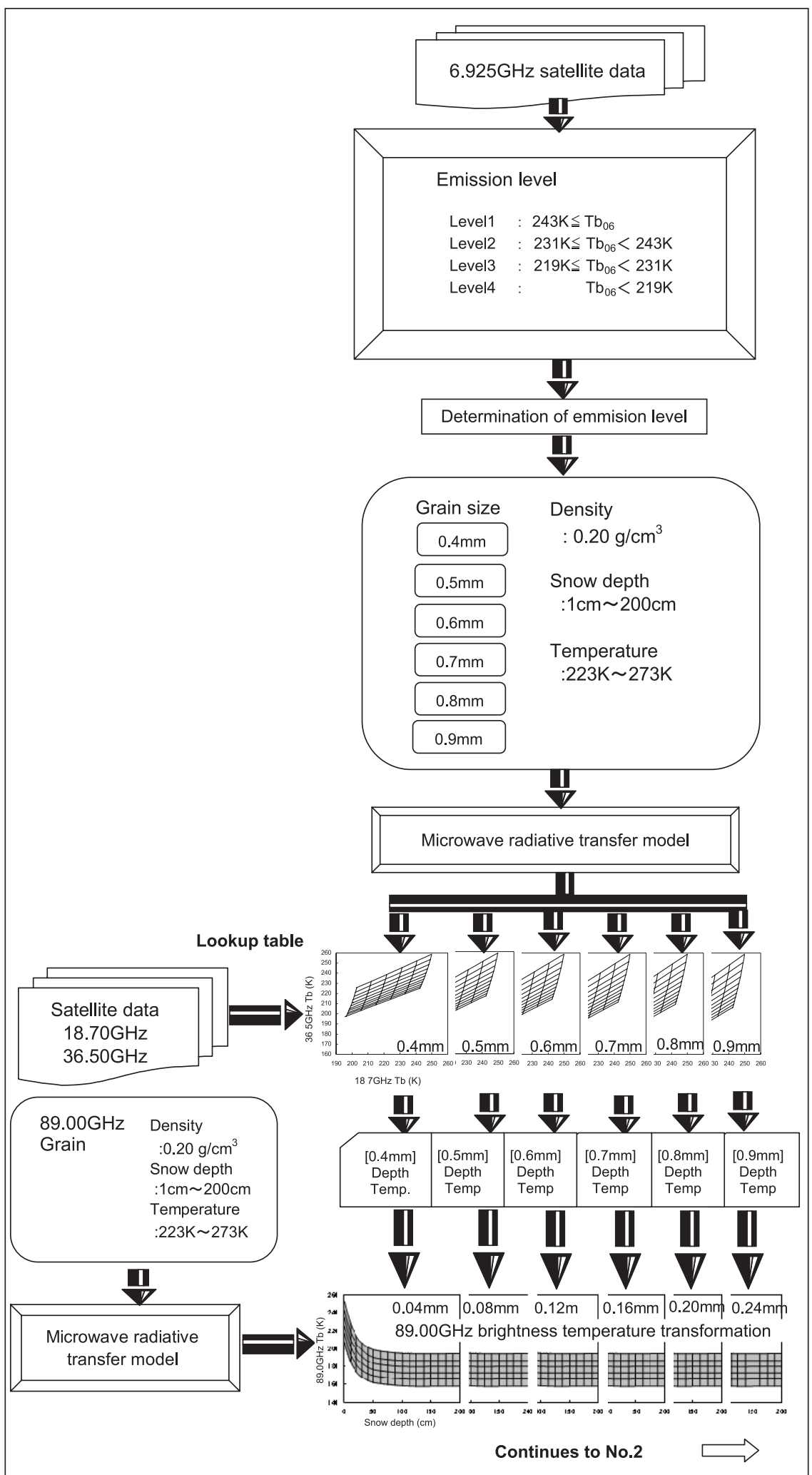

Fig. 15. (a) Structure of algorithm No. 1. 


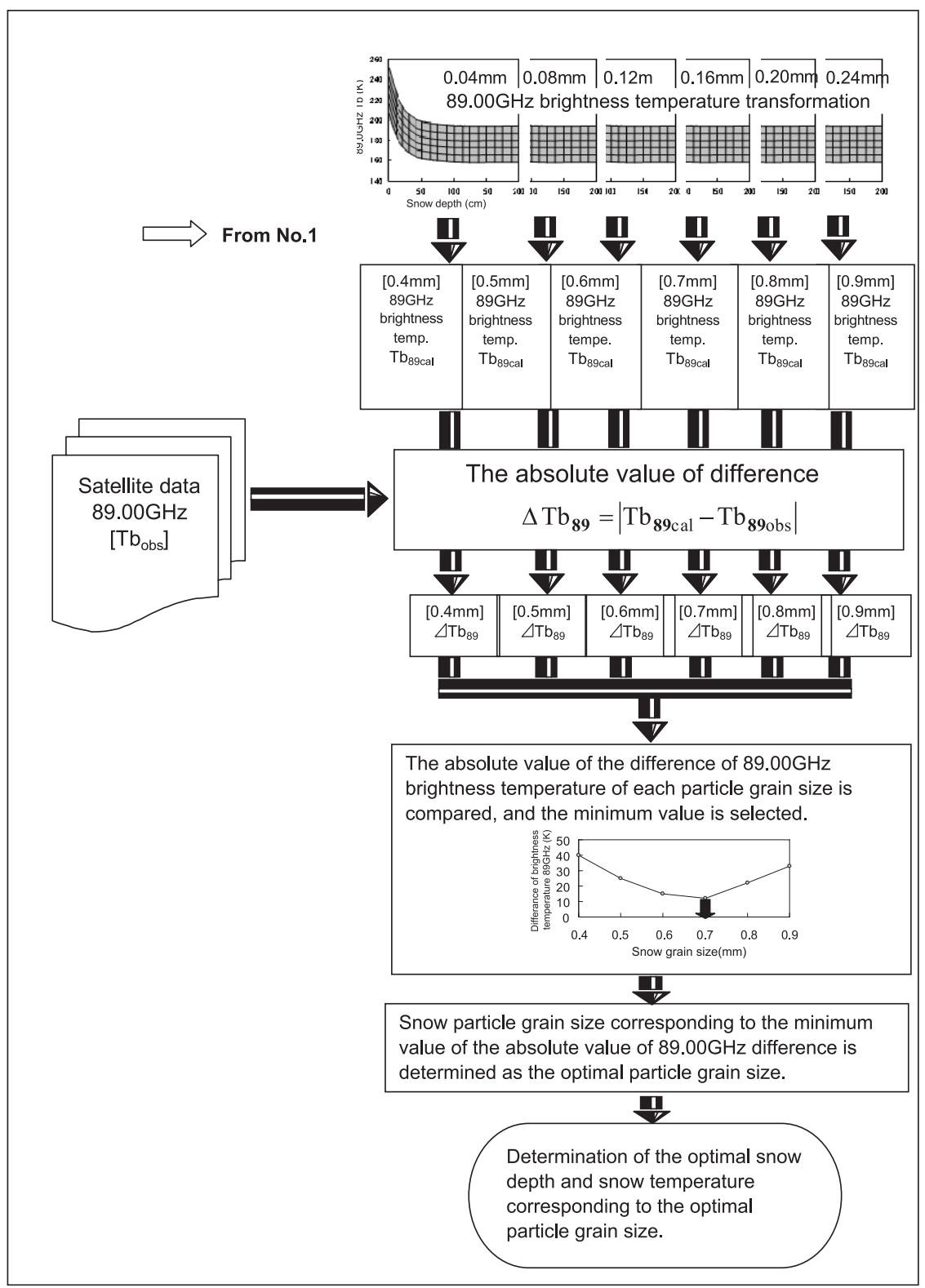

Fig. 15. (b) Structure of algorithm No. 2.

observed and calculated brightness temperatures at $89 \mathrm{GHz}$.

To verify the effect of grain size at $89 \mathrm{GHz}$ in our algorithm, we compared snow depths for an assumed grain size of $0.6 \mathrm{~mm}$ with depths based on the grain size to be evaluated. An assumed grain size of $0.6 \mathrm{~mm}$, as shown in Fig. 14 , results in an overestimate of snow depth (estimated data $(0.6 \mathrm{~mm}))$. In contrast, by ap- plying the grain-size evaluation technique for $89 \mathrm{GHz}$, we were able to select the optimal grain size for the model and thereby improve the accuracy of our estimate of snow depth (estimated data (optimal size)).

\subsection{Flow charts of the algorithms}

The snow-satellite algorithm developed in this study is shown in Fig. 15a,b. The flow 


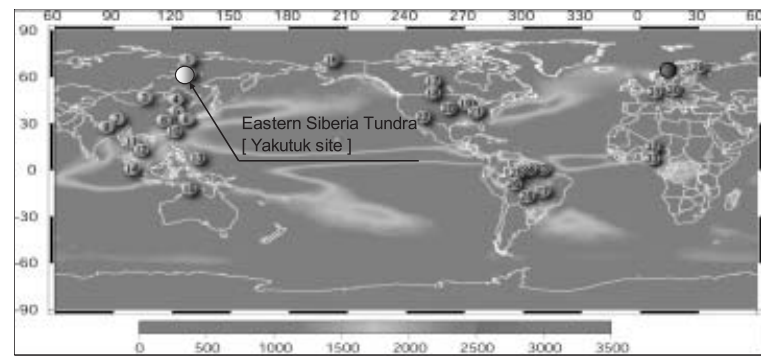

Fig. 16. Network of CEOP 36 reference sites and location of the Eastern Siberia Taiga reference site close to Yakutsk City, Saha Republic, Russian Federation.

chart of the algorithm shown in this figure is described below.

1) The emission level from the land surface and lookup-table position is determined from $6.925 \mathrm{GHz}(h)$ satellite brightness temperature.

2) A lookup table for 18.7 and $36.5 \mathrm{GHz}$ is created for each grain-size class using the radiative transfer model by varying the snow depth between 1 and $200 \mathrm{~cm}$ and the snow temperature between 223 and $273 \mathrm{~K}$. Snow density was assumed to $0.2 \mathrm{~g} \mathrm{~cm}^{-3}$.

3) The observed satellite brightness temperatures for 18.70 and $36.50 \mathrm{GHz}$ are used to select the corresponding snow depth from the lookup table for each grain-size class.

4) The $89 \mathrm{GHz}$ brightness temperature transformation table for each grain size is created using the microwave radiative transfer model by varying snow depth $(1-200 \mathrm{~cm})$ and snow temperature (223-273 K).

5) The $89 \mathrm{GHz}$ brightness temperature $\left(T_{b 89 c a l}\right)$ is calculated by inputting snow depth and snow temperature calculated for each grain size into the $89 \mathrm{GHz}$ brightness temperature transformation table calculated for each grain size.

6) The difference in the estimated $\left(T_{b 89 c a l}\right)$ and satellite-derived brightness temperature $\left(T_{b 89 o b s}\right)$ is calculated for each grain-size class and the optimal (minimum TB difference) grain-size class is selected.

7) Finally, the values of snow depth and snow temperature that correspond to the optimal snow grain-size are selected as the optimal snow depth and snow temperature.

\section{Validation of the algorithm}

\subsection{In situ snow observations conducted at the} CEOP Reference Site, Eastern Siberia

$\mathrm{CEOP}$ is an international project with 36 reference sites in different locations around the world (Fig. 16). At present, these are nine reference sites in cold regions: Eastern Siberia, Eastern Siberia Tundra, Eastern Siberia Taiga, Mongolia, Tibet, Himalayas, ARM North Slope of Alaska (Barrow), BERMS (Old Black Spruce), Sodankyla, and Norunda. We are currently undertaking observations of snow depth and air temperature at the Eastern Siberia Taiga site, which is located close to the city of Yakutsk within the Saha Republic, Russian Federation. Yakutsk is located along the Lena River. In general, Siberia is characterized by a discontinuous permafrost layer and an extensive area of forest known as the Taiga, which is covered by dry snow in winter.

The following seven observation sites have been operated by CEOP's researcher (Fig. 17):

- Larch forest: Larch site

- Pine forest: Pine and Viluy sites

- Mixed larch and pine: Molot site

- Open field: Tulagino, Kenkeme, and Khatassy sites

The observation targets at the seven sites are wintertime snow depth and air temperature. The observation instruments are installed in October each year when snow first falls and are removed in June with the melting of the snow cover. The observation of snow depth and temperature started in October 2000 and continues today; observation coverage is shown in Table 2. A sonic range sensor and a temperature sensor were used for taking measurements. Snow depth and temperature are recorded every 2 hours, with data stored in a data logger.

\subsection{Match-up data for validation of the algorithm}

Match-up data for the period from October 2002 to March 2003 were used to verify the algorithm. These data were based on brightness temperature data acquired by Aqua/AMSR-E and in situ observation data provided by JAXA. 


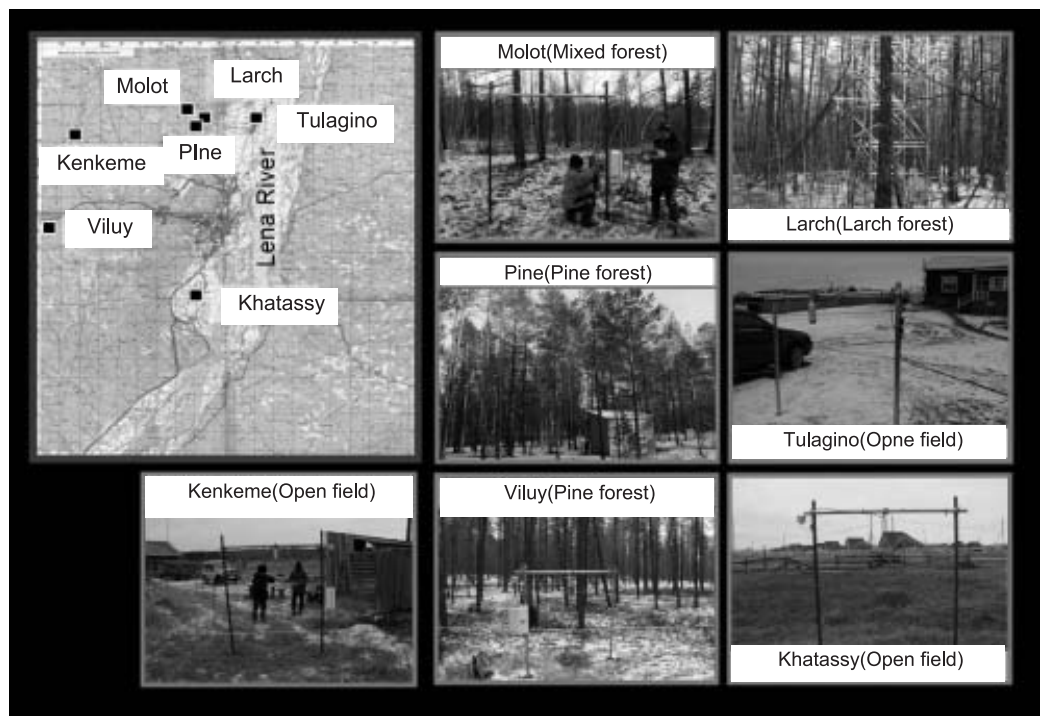

Fig. 17. Photographs of the Yakutsk observation site.

Table 2. Summary of observation data

\begin{tabular}{|c|c|c|c|c|c|c|c|c|}
\hline \multirow[b]{2}{*}{ Site } & \multirow[b]{2}{*}{ Condition } & Latitude & \multirow{2}{*}{$\begin{array}{c}\text { Observation } \\
\text { item }\end{array}$} & \multirow{2}{*}{$\begin{array}{l}2000.11 \\
-2001.5\end{array}$} & \multirow{2}{*}{$\begin{array}{l}2001.11 \\
-2002.5\end{array}$} & \multirow{2}{*}{$\begin{array}{l}2002.11 \\
-2003.5\end{array}$} & \multirow{2}{*}{$\begin{array}{l}2003.11 \\
-2004.5\end{array}$} & \multirow{2}{*}{$\begin{array}{l}2003.11 \\
-2004.5\end{array}$} \\
\hline & & Longitude & & & & & & \\
\hline \multirow{2}{*}{ Larch } & \multirow{2}{*}{ Larch forest } & $62.26 \mathrm{~N}$ & Snow depth & 0 & O & 0 & 0 & o \\
\hline & & $129.62 \mathrm{E}$ & Air temperature & O & O & O & O & O \\
\hline \multirow{2}{*}{ Pine } & \multirow{2}{*}{ Pine forest } & $62.24 \mathrm{~N}$ & Snow depth & - & O & O & O & O \\
\hline & & $129.65 \mathrm{E}$ & Air temperature & O & O & O & ○ & O \\
\hline \multirow{2}{*}{ Viluy } & \multirow{2}{*}{ Pine forest } & $62.06 \mathrm{~N}$ & Snow depth & - & O & O & ○ & O \\
\hline & & $129.10 \mathrm{E}$ & Air temperature & - & O & O & O & O \\
\hline \multirow{2}{*}{ Molot } & \multirow{2}{*}{ Mixed forest } & $62.27 \mathrm{~N}$ & Snow depth & - & O & 0 & 0 & O \\
\hline & & $129.55 \mathrm{E}$ & Air temperature & - & O & O & O & O \\
\hline \multirow{2}{*}{ Tulagino } & \multirow{2}{*}{ Open field } & $62.26 \mathrm{~N}$ & Snow depth & O & O & 0 & O & O \\
\hline & & $129.87 \mathrm{E}$ & Air temperature & O & O & O & O & - \\
\hline \multirow{2}{*}{ Kenkeme } & \multirow{2}{*}{ Open field } & $62.23 \mathrm{~N}$ & Snow depth & - & O & O & O & O \\
\hline & & $129.14 \mathrm{E}$ & Air temperature & - & O & O & 0 & O \\
\hline \multirow{2}{*}{ Khatassy } & \multirow{2}{*}{ Open field } & $61.90 \mathrm{~N}$ & Snow depth & - & O & O & O & O \\
\hline & & $129.62 \mathrm{E}$ & Air temperature & - & O & O & O & O \\
\hline
\end{tabular}

\subsection{Validation results}

Figure 18A shows a comparison of time series data and scatter plots showing in situ observations of snow depth and estimated snow depth for each site. An evaluation of the error in estimated snow depth is shown in Table 3.

We then calculated the RMSE based on the error between observed and estimated values 

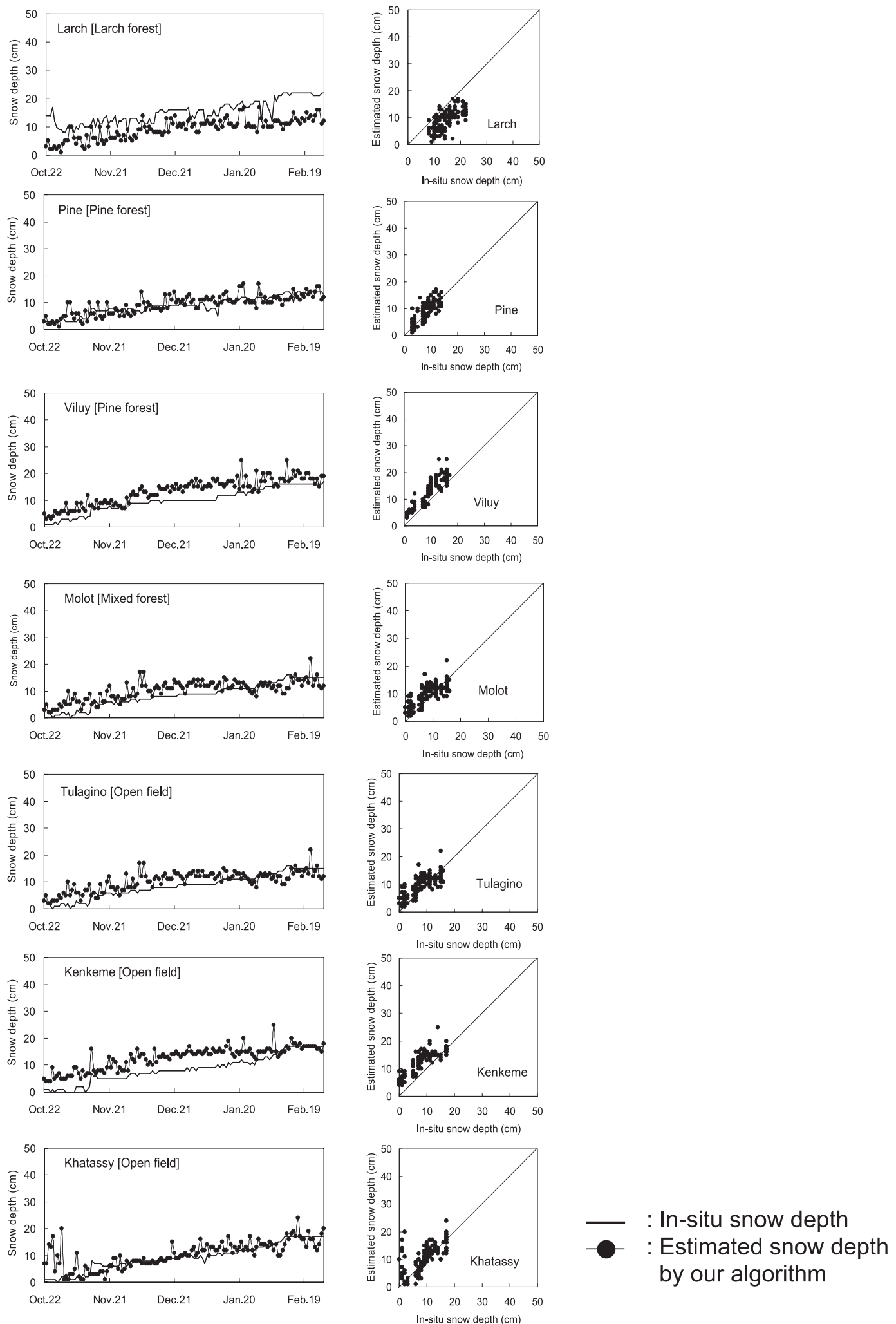

Fig. 18. Comparative time series and scatter plots showing in situ observed snow depth and estimated snow depth. Estimation period: October 2002 to March 2003. 


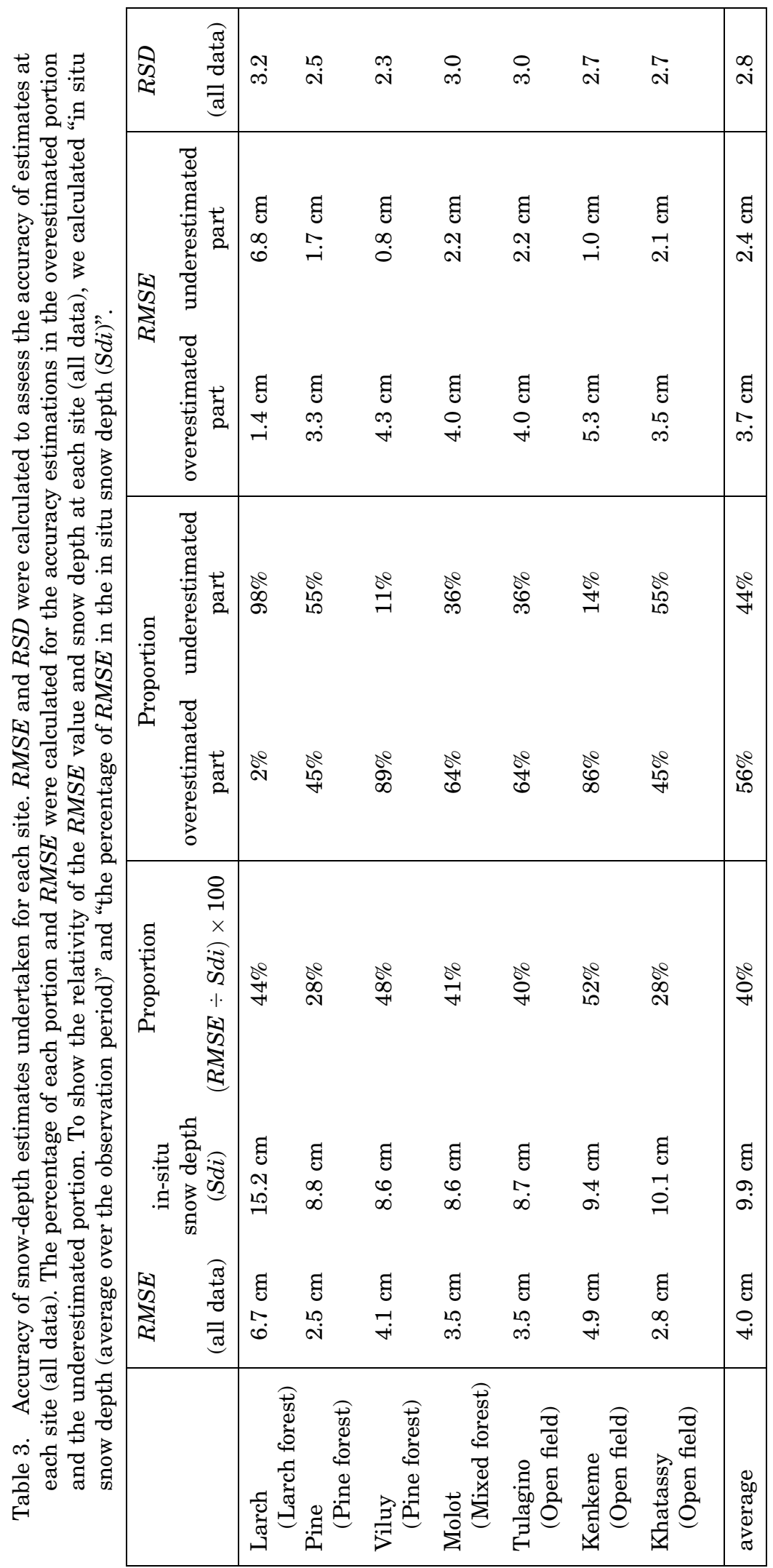




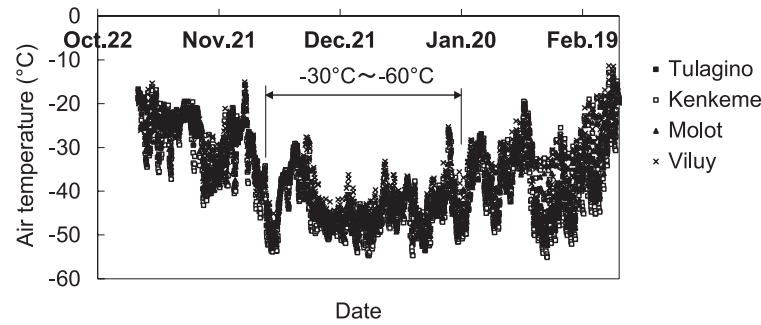

Fig. 19. Temporal variations in air temperature measured at the Viluy, Molit, Tulagino, and Kenkeme sites. Observation period: October 2002 to March 2003.

and the residual standard deviation (RSD) for all of the verification periods. We also calculated the proportion and RMSE of overestimated and underestimated values of snow depth. The average $R M S E$ is small $(4.0 \mathrm{~cm})$, and the average $R S D$ is 2.8 , indicating only minor variation. The estimated snow depth is therefore in relatively good agreement with the in situ data.

In terms of the seven different sites, the $R M S E$ for all of the verification periods at the Larch site is $6.7 \mathrm{~cm}$, which is slightly high. The algorithm underestimated snow depth (RMSE of $6.8 \mathrm{~cm}$ ) in $98 \%$ of cases. $R S D$ is also comparatively high, indicating large variations in the degree of underestimation. This poor estimation accuracy may reflect the influence of the branches and tree trunks of dense deciduous trees. At the Viluy, Molit, Tulagino, and Kenkeme sites, the algorithm overestimated snow depth in $60 \%$ of cases, although the overall $R M S E$ is low. This resulted in a reduction in the overall accuracy of the estimates. One factor that is common to these sites is that overestimation is most pronounced from the end of November to mid-January. This can be explained by the fact that air temperature during this winter period is very low at these sites (Fig. 19). Soil upon the permafrost freezes at this time, and the satellite observations penetrated the shallow snow pack and detected frozen soil as snow. In this way, snow depth was overestimated.

At the Pine and Khatassy sites, the overall $R M S E$ is $3 \mathrm{~cm}$ or less, and $R S D$ is 3 or less, indicating minor variations. The rates of overesti- mation and underestimation are approximately equal, with the RMSE of overestimates being higher than that for underestimates. These results might also have been slightly influenced by the misinterpretation of frozen soil as snow.

\subsection{Issues for future research \\ a Influence of forest (vegetation) cover on estimates of snow depth}

In using the proposed algorithm to estimate snow depth within the northern hemisphere, we detected the influence of forest (vegetation) cover on our estimates. A weak influence of forest was also detected in the underestimated snow depth calculated for the Larch site. To address this problem, we used the technique proposed by Koike et al. (1999) to evaluate the influence of the forest (vegetation) cover on our estimates. Koike et al. (1999) calculated the leaf area index $(L A I)$ based on the normalized difference vegetation index (NDVI), calculated vegetation moisture $(W c)$ from $L A I$, and finally calculated optical thickness $(\tau)$ from $W c$. The authors developed the technique of calculating the brightness temperature of vegetation from $\tau$. The brightness temperature of the vegetation represents radiation from the vegetation itself and the amount of radiation from the snow that is intercepted by the vegetation. This technique has the advantage of being readily applicable to the lookup table used in the present study.

We then estimated the snow depth at the forested Larch, Pine, Viluy, and Molot sites using a version of the algorithm that takes into account the technique proposed by Koike et al. (1999) to estimate vegetation. We used an $N D V I$ value of 0.2 , which is the annual average for the area based on NOAA/AVHRR. The result is shown in Fig. 20. Although the effect of the evaluation technique proposed by Koike et al. (1999) is apparent for deciduous larch forest, snow depth at the other sites, in evergreen forest, remained overestimated. On the basis of these results, we consider it necessary to develop a technique that evaluates the amount of snow on the crowns of evergreen trees. The future introduction of a model that describes snow on tree crowns would represent a significant advance in this field of research; moreover, we require analyses at the forest-scale rather than at the current footprint size. 


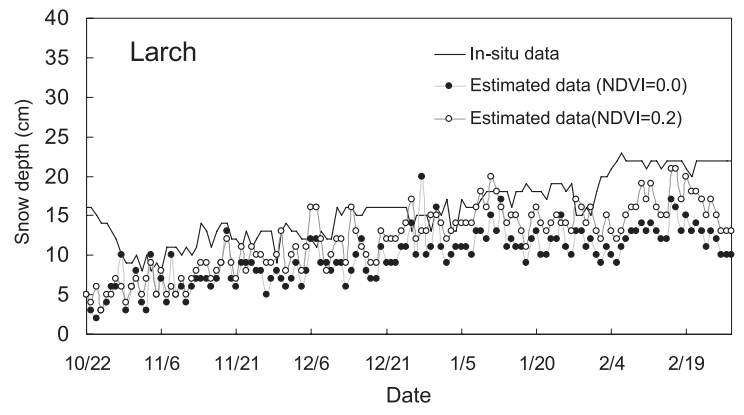

(a) Larch (deciduous tree zone)

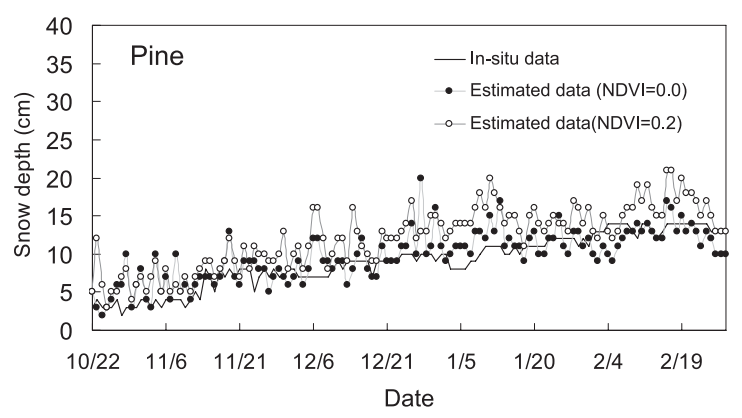

(b) Pine (evergreens tree zone)

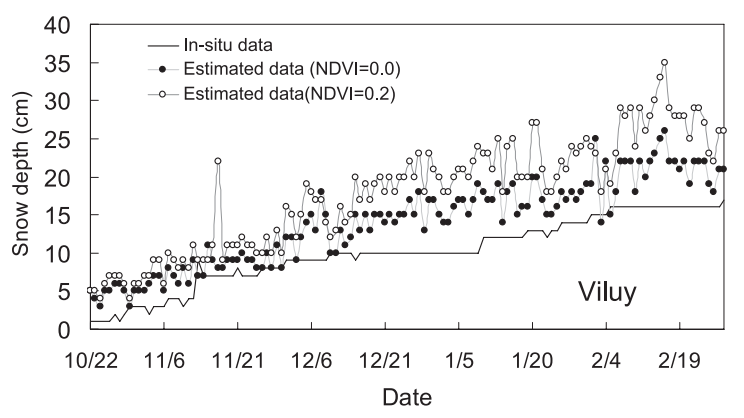

(c) Viluy (evergreens tree zone)

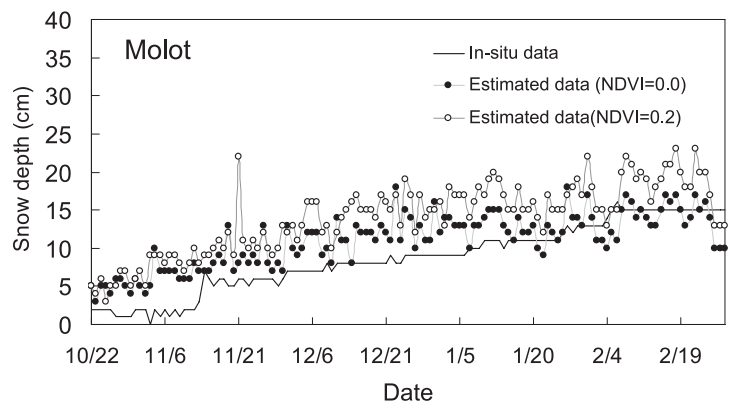

(d) Molot (evergreens tree zone)

Fig. 20. Estimation of snow depth using an algorithm that incorporated the vegetation-estimation technique of Koike et al. (1999). Estimation period: October 2002 to March 2003. $b$ Influence of frozen soil on estimates of snow depth

In cold permafrost regions, soil beneath the snow cover freezes in winter; under these conditions, a microwave radiometer detects frozen soil as snow. This phenomenon is apparent in the results of the present study. Accordingly, we analyzed the influence of frozen soil on estimates of snow depth, and consider it necessary to develop an algorithm that takes this factor into account.

\section{c Influence of cloud coverage on estimates of snow depth}

A current problem of our snow satellite algorithm is the high level of daily fluctuations in estimated snow depth. This problem occurs when the $89 \mathrm{GHz}$ microwave radiation is affected by cloud cover. For example, the results for the ground-based station located near the Ural Mountains in the Russian Federation (latitude $62^{\circ} 45^{\prime} \mathrm{N}$, longitude $66^{\circ} 05^{\prime} \mathrm{E}$ ) are shown in Fig. 21. The total amount of cloud [\%] based on GTS for this area shows that the region is commonly overcast (Fig. 21b). Variations in cloud coverage lead to daily fluctuations in recorded satellite brightness temperature. Daily fluctuations in brightness temperature lead to large daily fluctuations in estimated grain size (Fig. 21e) and snow depth (Fig. 21f); this problem needs to be considered in future versions of the algorithm.

We also observed that intense daily fluctuations in estimated snow depth are absent for seven sites in Yakutsk. We then investigated temporal changes in the total cloud cover [\%] based on GTS, the $89 \mathrm{GHz}$ brightness temperature, the difference between the 18.7 and $36.5 \mathrm{GHz}$ brightness temperatures, estimated snow depth, and the estimated snow grain-size at a ground-based station located close to Yakutsk (latitude $56^{\circ} 28^{\prime} \mathrm{N}$, longitude $131^{\circ} 13^{\prime} \mathrm{E}$ ) that is one of 81 ground-based stations in the northern hemisphere (Fig. 22).

As shown in Fig. 22b, there is less cloud cover at the station located close to Yakutsk than at the station located near the Ural Mountains (Fig. 21b). Consequently, daily fluctuations in estimated snow depth are absent at the Yakutsk site (Fig. 22f) because under relatively cloudless conditions the recorded variations in satellite brightness temperature and estimated 


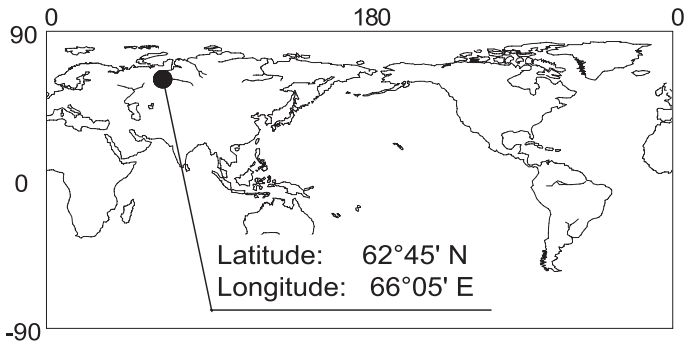

(a) Location

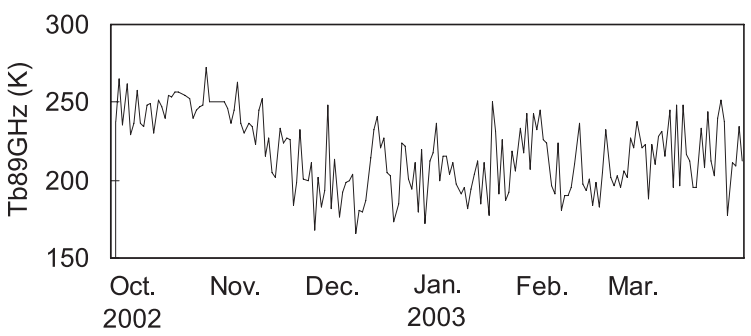

(c) $89 \mathrm{GHz}$ brightness temperature

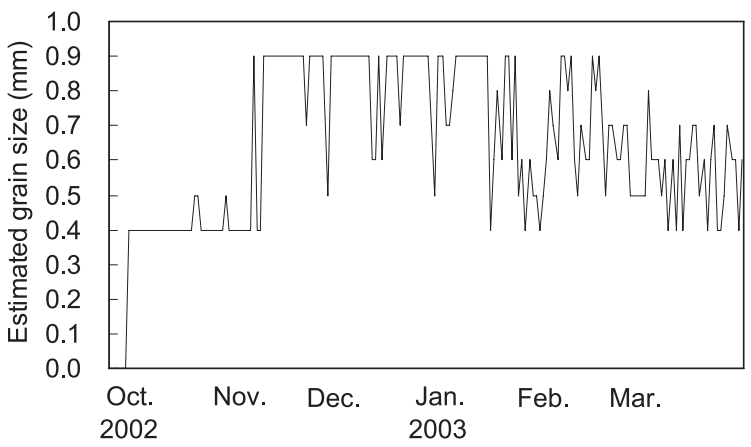

(e) Estimated snow grain size

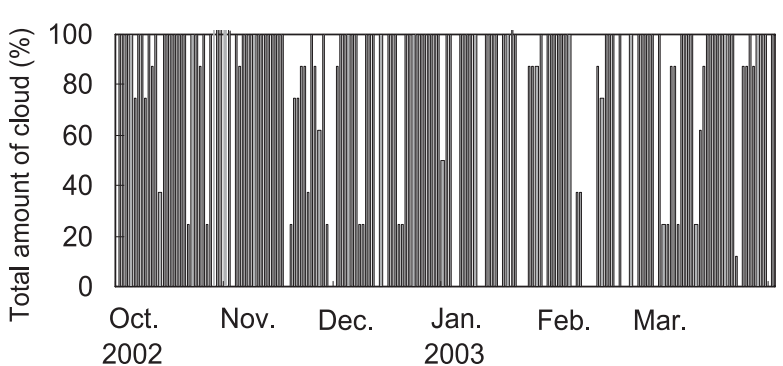

(b) Total amount of cloud (\%)

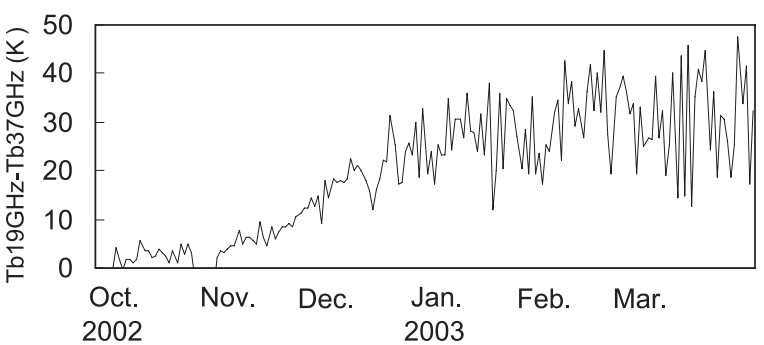

(d) Difference between 18.7 and $36.5 \mathrm{GHz}$

brightness temperature

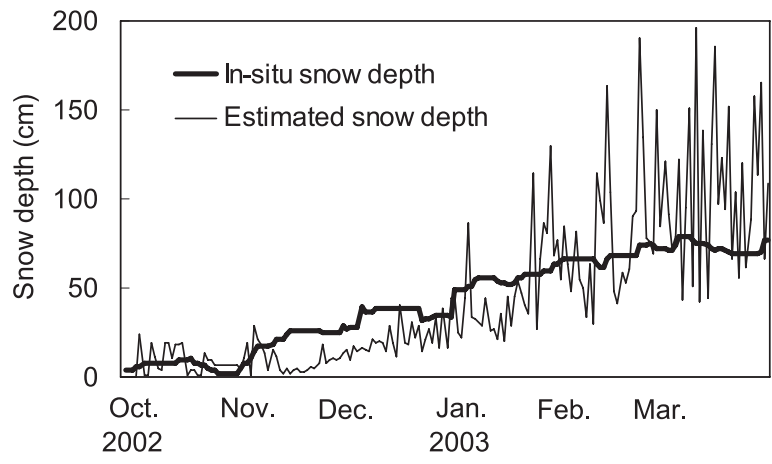

(f) Estimated snow depth

Fig. 21. Time series data for the ground-based station located close to the Ural Mountains, Russian Federation (latitude $62^{\circ} 45^{\prime} \mathrm{N}$, longitude $66^{\circ} 05^{\prime} \mathrm{E}$ ). (c): $89 \mathrm{GHz}$ brightness temperature that is used to estimate the grain size of snow. (d): difference between 18.7 and $36.5 \mathrm{GHz}$ brightness temperatures that are used to estimate snow depth.

grain size are less pronounced (Fig. 22c-e). Although the degree of influence of cloud cover varies spatially, we investigated a technique that simultaneously uses 89.0 and $10.65 \mathrm{GHz}$ radiation to negate the influence of clouds that is apparent when using just $89 \mathrm{GHz}$.

\section{Conclusion}

This paper describes a new snow algorithm for the Advanced Microwave Scanning Radio- meter (AMSR) and the AMSR for Earth Observation System (AMSR-E). We validated the algorithm using snow-depth data recorded at the CEOP Reference Site in Yakutsk. A new radiative transfer model for layered snow was developed by combining the 4-stream fast model and DMRM; this model is integrated into the new algorithm. The algorithm makes use of the multi-frequency channels of AMSR and AMSR-E in taking into account the effects 


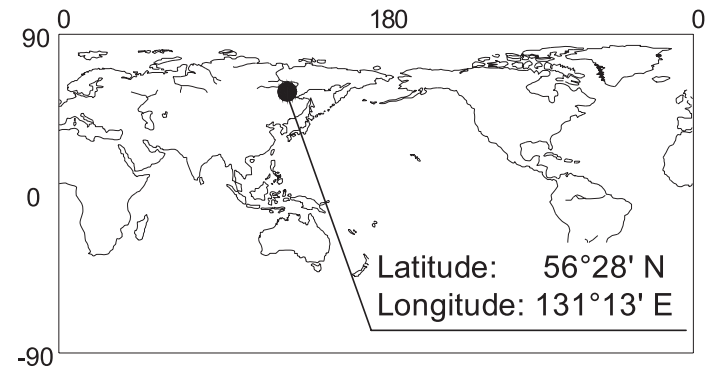

(a) Location

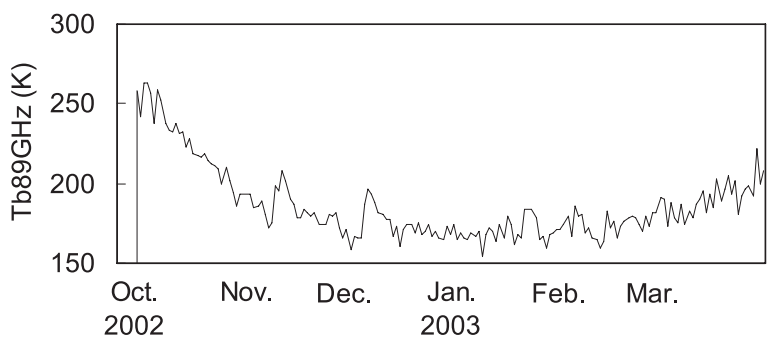

(c) $89 \mathrm{GHz}$ brightness temperature

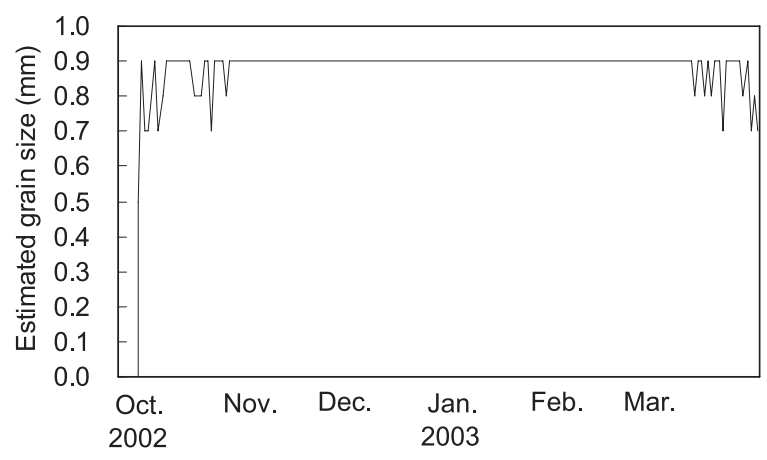

(e) Estimated snow grain size

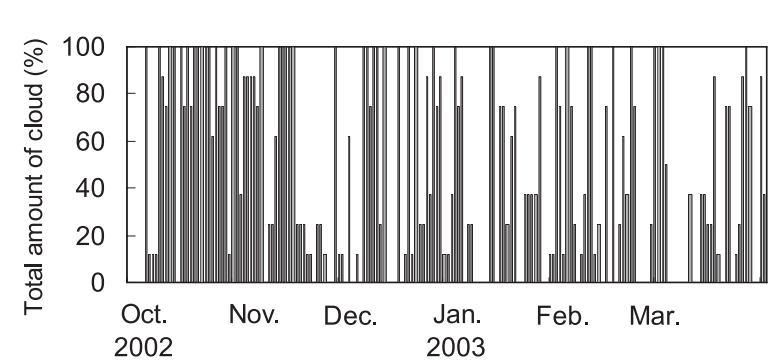

(b) Total amount of cloud (\%)

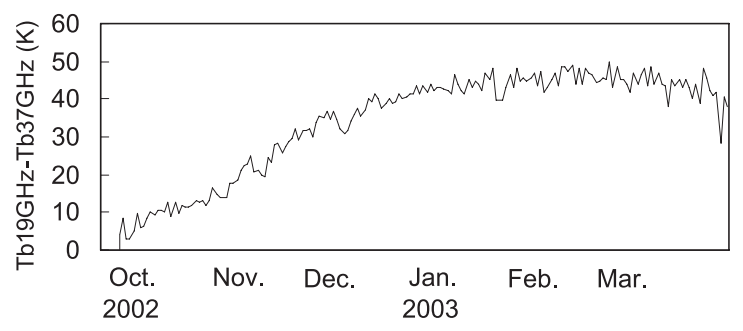

(d) Difference between 18.7 and $36.5 \mathrm{GHz}$ brightness temperature

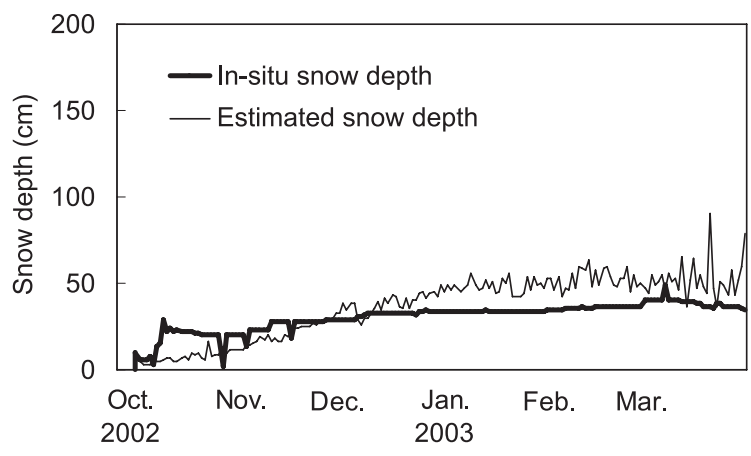

(f) Estimated snow depth

Fig. 22. Time series data for the ground-based station located close to Yakutsk. (latitude $56^{\circ} 28^{\prime} \mathrm{N}$, longitude $\left.131^{\circ} 13^{\prime} \mathrm{E}\right)$.

of land-surface conditions under the snow pack and snow grain-size on observations of brightness temperature in the microwave region.

We validated the algorithm for the period from October 2002 to March 2003 (EOP-3) at seven snow-measurement sites within the CEOP Reference Site in Yakutsk. We calculated the RMSE (root mean square error) from the error between observed and estimated values and calculated $R S D$ (residual standard deviation) for all verification periods. We also calculated the proportion and $R M S E$ of overestimates and underestimates of snow depth. The average $R M S E$ is low $(4.0 \mathrm{~cm})$, and the average $R S D$ is 2.8 , indicating only minor variation. Snow depth was overestimated in $56 \%$ of cases, and the average $R M S E$ of the overestimates is $3.9 \mathrm{~cm}$; the average $R M S E$ for underestimated values is $2.4 \mathrm{~cm}$. This indicates that the estimated snow depth is in relatively good agreement with in situ data.

As snow at Yakutsk is shallow and dry, it is suitable for estimating snow depth based on passive microwave observations. A greater challenge is the estimation of snow depth in deep-snow regions located in the northern 

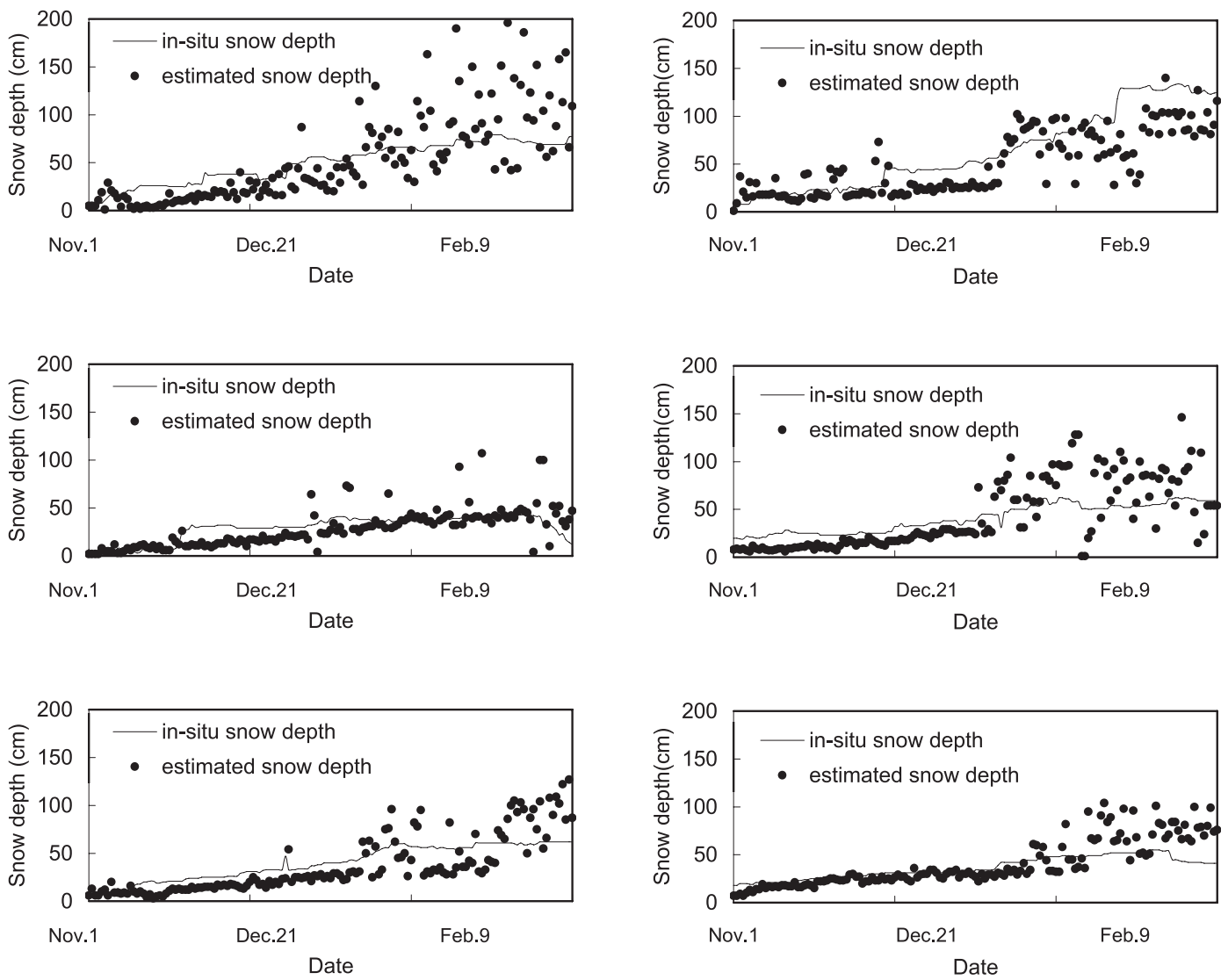

Fig. 23. Example of estimated snow depth for the period from October 2002 to March 2003 at the ground-based stations located in the northern hemisphere.

hemisphere. Examples of some of these regions are shown in Fig. 23; these results show that estimates for deep snow were improved by using our algorithm. However, the estimation accuracy is low for deep and wet snow during the thaw period. We consider this condition to be the estimation limit for snow depth based on passive microwave observation.

From the analyses at individual sites, we identified the influence of forest cover, frozen soil, and clouds (atmospheric attenuation) on the process of estimating snow cover using the algorithm. We consider atmospheric attenuation to be the most important issue, and are currently working on a solution to this problem.

\section{References}

Chang, A.T.C., J.L. Foster, D. Hall, A. Rango, and B. Hartline, 1982: Snow water equivalence determination by microwave radiometry. Cold Regions Science and Technology, 5, 259-267.
Chang, A.T.C., J.L. Foster, and D.K. Hall, 1987: Nimbus-7 derived global snow cover parameters, Annals of Glaciology, 9, 39-44.

Chang, A.T.C., J.L. Foster, and A. Rango, 1991: Utilization of surface cover composition to improve the microwave determination of snow water equivalent in a mountainous basin. International Journal of Remote Sensing, 12, 23112319.

England, A.W., 1975: Thermal microwave emission from a scattering layer, Journal of Geophysical Research, 88(32), 4484-4496.

Goodison, B.E. and A. Walker, 1993: Canadian development and use of snow cover information from passive microwave satellite data, ESA/ NASA Inter. Workshop on Passive Microwave Remote Sensing Related to Land-atmosphere interaction, pp 11-15.

Hallikainen, M.T. and P.A. Jolma, 1986: Retrieval of water equivalent of snow cover in Finland by satellite microwave radiometry. IEEE Trans. GRS, 24, 855-862. 
Jordan, R., 1991: A one-dimensional temperature model for a snow cover. CRREL Special Report 91-16, pp 64.

Kelly, R.E., A.T.C. Chang, L. Tsang, and J.L. Foster, 2003: A Prototype AMSR-E Global Snow Area and Snow Depth Algorithm. IEEE Transaction on geoscience and remote sensing, 41(2), 230241.

Koike, T. and T. Suhama, 1993: Passive-microwave remote sensing of snow, Annals of Glaciology, 18, 305-308.

Koike, T., J. Yoshimoto, K. Fujiharu, and A. Shibata, 1999: Development and evaluation of an satellite algorithm for global snow distribution, Journal of Hydroscience and Hydraulic Engineering, 43, 211-215.

Liu, G., 1998: A fast and Accurate Model for Microwave Radiance Calculations, Journal of the Meteorological Society of Japan, 76(2), 335343.

Marks, D., 1988: Climate, energy exchange, and snowmelt in Emerald Lake watershed, Ph. D. dissertation, Sierra Nevada, University of California, Santa Barbara.
Mätzler, C., 1987: Applications of the interaction of microwaves with the natural snow cover. $R e$ mote Sensing Rev., 2, 259-391.

Sturm, M., J. Holmgren, and G.E. Liston, 1995: A seasonal snow cover classification system for local to global applications. Journal of Climate, 8, 1261-1283.

Tsang, L. and J.A. Kong, 1992: Scattering of electromagnetic waves from a dense medium consisting of correlated Mie scatterers with size distributions and applications to dry snow. J. EM Waves and Applications, 6, 265-286.

Tsang, L., C.T. Chen, A.T.C. Chang, J.J. Guo, and K.H. Ting, 2000: Dense media radiative transfer theory based on quasicrystalline approximation with applications to passive remote sensing of snow. Radio Science, 35(3), 731.

Wilson, L., L. Tsang, J.-N. Hwang, and Chi-Te Chen, 1999: Mapping snow water equivalent in mountainous areas by combining a spatially distributed snow hydrology model with passive microwave remote sensing data, IEEE Transactions on Geoscience and Remote Sensing, 37(2), 690-704. 